\title{
Inhibitors of Bacterial Signal Peptidase: A Series of 6-(Substituted oxyethyl)penems
}

\author{
Aileen Allsop, Gerald Brooks*, Peter D. Edwards, \\ Arun C. Kaura and Robert Southgate \\ SmithKline Beecham Pharmaceuticals, \\ Brockham Park, Betchworth, Surrey, RH3 7AJ, UK
}

(Received for publication March 18, 1996)

\begin{abstract}
A series of 6-(substituted oxyethyl)penem esters having the $(5 S)$ stereochemistry which are potent inhibitors of Escherichia coli leader peptidase is described. Structure-activity relationships are discussed.
\end{abstract}

Protein secretion in bacteria is becoming a pathway of widespread interest for the derivation of antibacterial agents ${ }^{1}$. The final destination of considerable quantities of protein (up to $20 \%$ ) synthesised by bacteria lies outside the cytoplasm. The cytoplasmic membrane represents a hydrophobic barrier which must be crossed by all of these proteins. Signal peptidases ensure release of secreted proteins from the outer surface of the plasma membrane by removal of the hydrophobic signal sequence, or cleavable membrane anchor, from the pre-proteins ${ }^{2}$. These signal peptidases represent attractive targets for novel antibacterial agents.

In $E$. coli there appears to be an essential enzyme, leader peptidase, which fulfils the signal peptidase function $^{3,4)}$. It is anchored to the membrane by two hydrophobic domains and the catalytic portion of the molecule is located in the periplasm ${ }^{5}$.

We have reported briefly that C-3 esters and amides of penems having the $5 S$ stereochemistry are inhibitors of $E$. coli leader peptidase, and that of particular interest were the 6-substituted penems (1a and $\mathbf{1 b}$ ), with $5 S, 6 S$, $1^{\prime} R$ stereochemistry ${ }^{6)}$. We now wish to report the synthesis and structure-activity relationships of a series of derivatives of $\mathbf{1 a}$.

\section{Chemistry}

It appeared that an efficient approach to the synthesis of homochiral $5 S$ penems could make use of well established methods for synthesis of $5 R$ penems followed by a photoisomerisation at $\mathrm{C}-5^{7}$. Thus the preparation of 1a was from the monocyclic $\beta$-lactam (2) ${ }^{8}$. The $5 R$ penem system was built up by the commonly used phosphorane route, and then subjected to UV irradiation from a medium pressure lamp to provide an equilibrium

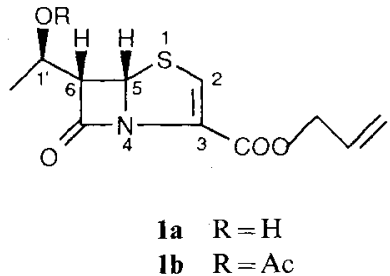

Scheme 1.

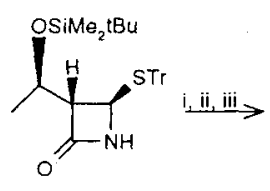

2

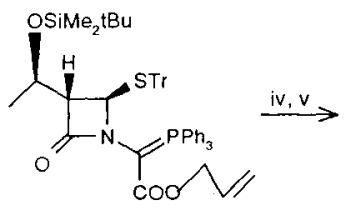

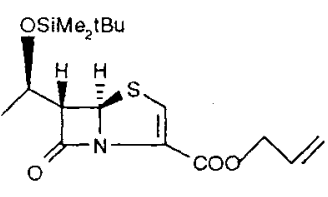

4

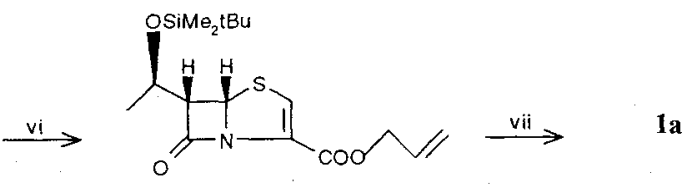

1w

Reagents: (i) allyl glyoxylate, (ii) $\mathrm{SOCl}_{2}, 2,6$-lutidine, (iii) $\mathrm{PPh}_{3}, 2,6$-lutidine (70\% for i iii), (iv) $\mathrm{AgNO}_{3}$, pyridine, $\mathrm{MeOH}$, (v) acetic formic anhydride, DMAP, $\mathrm{Et}_{3} \mathrm{NHCl}\left(85 \%\right.$ for iv v), (vi) hv (62\%), (vii) $\mathrm{Bu}_{4} \mathrm{NF}, \mathrm{HOAc}(95 \%)$. 
Table 1. Structures of intermediates.

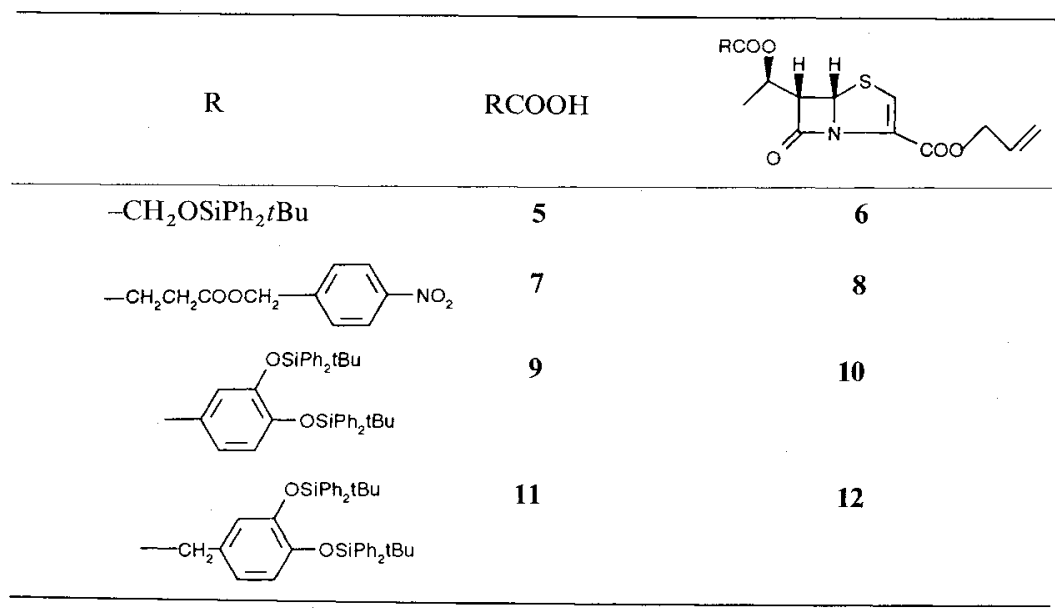

Table 2. Inhibition of leader peptidase.

\begin{tabular}{|c|c|c|c|c|}
\hline & \multirow{2}{*}{$\mathrm{R}$} & \multirow{2}{*}{$\mathrm{I}_{50} \mu \mathrm{m}$} & \multicolumn{2}{|c|}{$\%$ Inhibition at: } \\
\hline & & & $10 \mu \mathrm{m}$ & $1 \mu \mathrm{m}$ \\
\hline 1a & $\mathrm{H}$ & $<1$ & & \\
\hline $\mathbf{1 b}$ & $\mathrm{COMe}$ & $<1$ & & \\
\hline $1 \mathrm{c}$ & $\mathrm{CO}\left(\mathrm{CH}_{2}\right)_{14} \mathrm{Me}$ & & 0 & 0 \\
\hline 1d & $\mathrm{COCH}_{2} \mathrm{OH}$ & $<1$ & & \\
\hline $1 e$ & $\mathrm{COCH}_{2} \mathrm{CH}_{2} \mathrm{COO}^{-} \mathrm{Na}^{+}$ & 12.8 & & \\
\hline If & & 13.2 & & \\
\hline $1 \mathrm{~g}$ & & & 0 & 0 \\
\hline 1h & & & 0 & 0 \\
\hline $1 \mathrm{j}$ & $\mathrm{COPh}$ & 1.65 & & \\
\hline 1k & & & 21 & 0 \\
\hline 11 & & & 100 & 76 \\
\hline $1 \mathrm{~m}$ & $-\mathrm{OH}$ & 1.2 & & \\
\hline $1 \mathrm{n}$ & $\mathrm{COCH}_{2}^{-}$ & $<1$ & & \\
\hline $1 p$ & $\mathrm{CONH}_{2}$ & & 92 & 28 \\
\hline $1 q$ & CONHMe & $<1$ & & \\
\hline $1 \mathbf{r}$ & CONHPh & & 24 & 11 \\
\hline 1s & $\mathrm{Me}$ & 1.4 & & \\
\hline 1t & Et & $<1$ & & \\
\hline 1u & $\mathrm{CH}_{2} \mathrm{OMe}$ & 1.25 & & \\
\hline $1 v$ & $\mathrm{CH}_{2} \mathrm{COOEt}$ & & 100 & 27 \\
\hline $1 w$ & $\mathrm{SiMe}_{2} t \mathrm{Bu}$ & & 0 & 0 \\
\hline $1 x$ & $\mathrm{SO}_{3}^{-} \mathrm{Na}^{+}$ & & 26 & 0 \\
\hline
\end{tabular}


mixture of $5 R$ and $5 S$ penems. The $5 S$ penem (1w) could be isolated in $62 \%$ yield and recovered $5 R$ penem recycled. The hydroxyethyl penem (1a) was obtained by desilylation (Scheme 1).

In order to probe the requirements for enzyme inhibition, a variety of derivatives of penem (1a) were prepared: the secondary hydroxyl was acylated, alkylated and sulfonated. The substituents included two acidic groups, as in 1e and $\mathbf{1 x}$, and one weakly basic group as in 1n as well as a variety of neutral groups. Protected amino acid substituents $(\mathbf{1 f}, \mathbf{1 g}, \mathbf{1 h})$ or carbamate substituents (1p, 1q, 1r), might mimic a peptide substrate.

Acetic anhydride gave $\mathbf{1 b}$ and palmitoyl and benzoyl chlorides 1c and 1j. Appropriate isocyanates provided 1p, 1q, 1r. Other acyl derivatives were prepared using carboxylic acids (sometimes suitably protected), carbodiimide and DMAP (4-dimethylamino pyridine) ${ }^{9)}$. The protected carboxylic acids $(5,7,9$ and 11) which were used, and penem intermediates $(6,8,10$ and 12$)$ prepared from them, are shown in Table 1.

Ethers were prepared by standard methods. The sulfate (1x) was prepared using TMS chlorosulfate in pyridine.

$$
\text { Biology }
$$

The enzyme assay used for these compounds has been described ${ }^{6)}$. The synthetic nonapeptide Phe-Ser-Ala-SerAla-Leu-Ala-Lys-Ile- $\mathrm{NH}_{2}$ was used as substrate in the assay. Peptide concentration was $500 \mu \mathrm{M}$ and enzyme concentration $2 \mu \mathrm{M}$. Table 2 shows $I_{50}$ results for the compounds, or if this was not determined, the \% inhibition at compound concentrations of $10 \mu \mathrm{M}$ and $1 \mu \mathrm{M}$. The limit of detection of the assay was such that $I_{50}$ figures of below $1 \mu \mathrm{M}$ cannot be quoted accurately.

Amongst acyl derivatives, larger hydrophobic groups reduce activity from that of acetyl (1b): palmitoyl (1c) has no activity, benzoyl (1j) and diacetoxybenzoyl (1k) reduced activity. However, the two catechols (11, 1m) show quite good activity. The inactivity of the two phenylalanine derivatives $(\mathbf{1 g}, \mathbf{1 h})$ probably indicates intolerance of two large groups on the $\alpha$ carbon of the substituent, since the alanine derivative (1f) is active. The weakly basic pyridine (1n) is well tolerated but the ionised carboxylate (1e) much less so (the ionised sulfate $(\mathbf{1 x})$ is also poorly active). The glycolate (1d) has good activity.

Of the carbamates, the $N$-methyl (1q) is far superior to unsubstituted (1p) or $N$-phenyl (1r). Again, in the ether series, a large hydrophobic group (TBDMS, 1w) destroys activity, The ethyl ether (1t) is preferred, but other small alkyl groups are also active.

In summary, a few compounds appear in this assay to have a similar degree of activity to the initial leads (1a and $\mathbf{1 b}$ ). These have substituents which are unionised and either small (some ethers, 1d, 1q, can be hydrophilic or hydrophobic) or a little larger but hydrophilic $(\mathbf{1 1}, \mathbf{1 m}$, 1n). However, the lack of any significantly better activity than that of (1a or 1b) suggests that none of the other substituents offers considerably increased binding to the enzyme.

None of these compounds showed antibacterial activity at a useful level against a range of organisms in a standard MIC test. However, by means of a whole cell pulse-chase assay it has been demonstrated that compounds (1a, 1b and 1q) do inhibit processing of preproteins in the cytoplasmic membranes of certain strains of $E$. coli and Staphylococcus aureus. It has also been shown by biophotometer studies that the presence of $\mathbf{1 a}$ and $\mathbf{1 b}$ results in lowered growth rates of certain microorganisms. These results will be reported in detail elsewhere.

\section{Experimental}

All compounds were chromatographically pure as shown by TLC on Merck silica gel $60 \mathrm{~F}_{254}$ plates. Chromatography was carried out using Merck Silica gel 60 , eluting with EtOAc-hexane mixtures unless otherwise stated. Optical rotations were measured on an AA-1000 polarimeter (Optical Activity Ltd). IR spectra were recorded on a Perkin-Elmer 1605 FTIR, NMR spectra at $250 \mathrm{MHz}$ on a Bruker AC-F 250 machine and UV spectra on a Beckman DU-68 spectrophotometer. Mass spectra: EI and CI spectra were obtained on a VG TRIO-2, FAB spectra on a VG ZAB using Xe gas, and electrospray spectra on a Finnigan MAT TSQ700 instrument. MPs were determined on a Kofler hot stage apparatus and are uncorrected. All new compounds gave satisfactory IR, NMR, UV and MS and/or microanalysis. Compound $\mathbf{5}$ was prepared as previously ${ }^{10}$.

\section{Phosphorane (3)}

A solution of azetidinone (2) $(1 \mathrm{~g}, 2 \mathrm{mmol})$ and allyl glyoxylate $(340 \mathrm{mg}, 3 \mathrm{mmol})$ in benzene $(10 \mathrm{ml})$ was refluxed under a Dean-Stark apparatus for 1 hour, cooled and treated with $\mathrm{Et}_{3} \mathrm{~N}(0.1 \mathrm{ml})$. After 90 minutes the solution was evaporated and the residue redissolved in THF $(18 \mathrm{ml})$, cooled to $-20^{\circ} \mathrm{C}$ and treated with 2,6 -lutidine $(0.47 \mathrm{ml})$ and thionyl chloride $(0.23 \mathrm{ml})$. The mixture was warmed to room temperature, filtered and evaporated. The residue was taken up in benzene $(20 \mathrm{ml})$ and evaporated, then taken up in dioxan $(1.5 \mathrm{ml})$ and treated with 2,6 -lutidine $(0.47 \mathrm{ml})$ and triphenylphosphine $(4 \mathrm{~g})$. After stirring at $40^{\circ} \mathrm{C}$ for 18 hours, the mixture was diluted with EtOAc, washed with $0.5 \mathrm{~N} \mathrm{HCl}$ and water, dried and evaporated. Chromatography 
provided 3 as a foam $(1.2 \mathrm{~g}, 70 \%)$ : IR $v_{\max }\left(\mathrm{CHCl}_{3}\right) \mathrm{cm}^{-1}$ $1750,1615,1260,1105$

Allyl $\left(5 R, 6 S, 1^{\prime} R\right)-6$-( $1^{\prime}-t$-Butyldimethylsilyloxyethyl)penem-3-carboxylate (4)

A solution of phosphorane (3) $(1.2 \mathrm{~g}, 1.39 \mathrm{mmol})$ in $\mathrm{CH}_{2} \mathrm{Cl}_{2}(1.5 \mathrm{ml})-\mathrm{MeOH}(10 \mathrm{ml})$ was treated with pyridine $(0.146 \mathrm{ml}, 1.81 \mathrm{mmol})$ and a $0.15 \mathrm{M}$ solution of $\mathrm{AgNO}_{3}$ in $\mathrm{MeOH}(12.1 \mathrm{ml})$. After 30 minutes the solution was evaporated and remaining $\mathrm{MeOH}$ chased off with $\mathrm{CHCl}_{3}$. The residue was dissolved in $\mathrm{CH}_{2} \mathrm{Cl}_{2}(18 \mathrm{ml})$, ice-cooled and treated with acetic formic anhydride $(1.12 \mathrm{ml})$, DMAP $(0.17 \mathrm{~g})$ and $\mathrm{Et}_{3} \mathrm{NHCl}(1.93 \mathrm{~g})$. After stirring for 30 minutes the solid was filtered off, the filtrate diluted with EtOAc $(100 \mathrm{ml})$, washed with $0.5 \mathrm{~N} \mathrm{HCl}$, water and $\mathrm{NaHCO}_{3}$ solution, dried and allowed to stand for 1.5 hours to complete the cyclisation to penem. Chromatography provided the $5 R$-penem (4) (437 mg, 85\%). A sample crystallised from hexane/pentane as colourless needles: MP $91 \sim 93^{\circ} \mathrm{C} ;[\alpha]_{\mathrm{D}}^{22}+142^{\circ}\left(c 0.9 ; \mathrm{CHCl}_{3}\right)$; IR $v_{\max }(\mathrm{KBr}) \mathrm{cm}^{-1} 1771,1705,1557 ;{ }^{1} \mathrm{H} \mathrm{NMR}\left(\mathrm{CDCl}_{3}\right)$ $\delta 0.10\left(6 \mathrm{H}, \mathrm{s}, \mathrm{Me}_{2} \mathrm{Si}\right), 0.90(9 \mathrm{H}, \mathrm{s}, t \mathrm{Bu}), 1.27(3 \mathrm{H}, \mathrm{d}, J=$ $\left.6 \mathrm{~Hz}, \mathrm{CH}_{3} \mathrm{CH}-\right), 3.6 \sim 3.7(1 \mathrm{H}, \mathrm{m}, 6-\mathrm{H}), 4.25$ (1H, quintet, $\left.J=6 \mathrm{~Hz}, \mathrm{CH}_{3} \mathrm{CH}-\right), 4.6 \sim 4.8\left(2 \mathrm{H}, \mathrm{m},-\mathrm{CH}_{2} \mathrm{CH}=\right)$, $5.2 \sim 5.5\left(2 \mathrm{H}, \mathrm{m}, \mathrm{CH}_{2}=\mathrm{CH}-\right), 5.72(1 \mathrm{H}, \mathrm{d}, J=1.7 \mathrm{~Hz}$, $5-\mathrm{H}), \quad 5.8 \sim 6.1\left(1 \mathrm{H}, \mathrm{m}, \mathrm{CH}_{2}=\mathrm{CH}-\right), 7.23(1 \mathrm{H}, \mathrm{d}$, $J=0.9 \mathrm{~Hz}, 2-\mathrm{H}$ ); UV $\lambda_{\text {max }}^{\mathrm{EtOH}} \mathrm{nm}(\varepsilon) 260$ (2970), 317 (6830); FAB-MS (matrix 3-NOBA-Na) $m / z 392(100 \%, \mathrm{M}+$ $\mathrm{Na}$.

$$
\begin{aligned}
& \text { Anal Calcd for } \mathrm{C}_{17} \mathrm{H}_{27} \mathrm{NO}_{4} \mathrm{SSi} \text { : } \\
& \text { C 55.3, H 7.4, N 3.8, S 8.7. } \\
& \text { Found: } \\
& \text { C 55.3, H 7.6, N 3.8, S 8.7. }
\end{aligned}
$$

Allyl $\left(5 S, 6 S, 1^{\prime} R\right)-6-\left(1^{\prime}-t\right.$-Butyldimethylsilyloxyethyl)penem-3-carboxylate (1v)

A solution of penem (4) $(247 \mathrm{mg})$ in EtOAc $(100 \mathrm{ml})$ in the vessel of a photochemical reactor was purged with argon for 2 hours and then irradiated through pyrex by a Hanovia medium pressure UV lamp for 30 minutes. The solution was evaporated and chromatographed; the first-eluted compound was the required $5 S$-penem (112 mg, 45\%) as a white solid: $[\alpha]_{\mathrm{D}}^{21}-214^{\circ}$ (c 0.7 , $\left.\mathrm{CHCl}_{3}\right) ; \mathrm{IR} v_{\max }(\mathrm{KBr}) \mathrm{cm}^{-1} 1796,1712,1650,1557 ;{ }^{1} \mathrm{H}$ NMR $\left(\mathrm{CDCl}_{3}\right) \delta 0.12\left(6 \mathrm{H}, \mathrm{s}, \mathrm{Me}_{2} \mathrm{Si}\right), 0.88(9 \mathrm{H}, \mathrm{s}, t \mathrm{Bu})$, $1.43\left(3 \mathrm{H}, \mathrm{d}, J=6 \mathrm{~Hz}, \mathrm{CH}_{3} \mathrm{CH}-\right), 3.92(1 \mathrm{H}, \mathrm{ddd}, J=10.5$, 4.3 and $0.7 \mathrm{~Hz}, 6-\mathrm{H}), 4.37(1 \mathrm{H}, \mathrm{dq}, J=10.1$ and $6 \mathrm{~Hz}$, $\left.\mathrm{CH}_{3} \mathrm{CH}-\right), 4.6 \sim 4.8\left(2 \mathrm{H}, \mathrm{m},-\mathrm{CH}_{2} \mathrm{CH}=\right), 5.2 \sim 5.5(2 \mathrm{H}$, $\left.\mathrm{m}, \mathrm{CH}_{2}=\mathrm{CH}-\right), 5.81(1 \mathrm{H}, \mathrm{d}, J=4.2 \mathrm{~Hz}, 5-\mathrm{H}), 5.9 \sim 6.1$ $\left(1 \mathrm{H}, \mathrm{m}, \mathrm{CH}_{2}=\mathrm{CH}-\right), 7.33(1 \mathrm{H}, \mathrm{d}, J=0.7 \mathrm{~Hz}, 2-\mathrm{H}) ; \mathrm{UV}$ $\lambda_{\max }^{\mathrm{EtOH}} \mathrm{nm}(\varepsilon) 255$ (2950), 314 (7570); FAB-MS (matrix 3-NOBA-Na) $m / z 392(100 \%, \mathrm{M}+\mathrm{Na})$.

Anal Calcd for $\mathrm{C}_{17} \mathrm{H}_{27} \mathrm{NO}_{4} \mathrm{SSi}$ : Found:

C 55.3, H 7.4, N 3.8 . C 55.3, H 7.6, N 3.9.

The second-eluted compound was recovered (4) (89 mg, 36\%).
Allyl (5S,6S, $\left.1^{\prime} R\right)-6-\left(1^{\prime}\right.$-Hydroxyethyl)penem-3carboxylate (1a)

Silylated penem (1v) (1.94 g, $5.25 \mathrm{mmol})$ was dissolved in $\mathrm{AcOH}(3.6 \mathrm{ml}, 63 \mathrm{mmol})$ and treated with a $1 \mathrm{M}$ solution of TBAF in THF $(21 \mathrm{ml})$. After 7 hours, the solution was diluted with EtOAc $(150 \mathrm{ml})$, washed with water (twice) and $\mathrm{NaHCO}_{3}$ solution, dried and evaporated. Chromatography gave (1a) as a pale yellow gum $(1.27 \mathrm{~g}$, 95\%): $[\alpha]_{\mathrm{D}}^{24}-249^{\circ}\left(c 1.6, \mathrm{CHCl}_{3}\right)$; IR $v_{\max }\left(\mathrm{CHCl}_{3}\right)$ $\mathrm{cm}^{-1} 3600,3510$ (br), 1796, 1710, 1650, 1560; ${ }^{1} \mathrm{H}$ NMR $\left(\mathrm{CDCl}_{3}\right) \delta 1.47\left(3 \mathrm{H}, \mathrm{d}, J=6 \mathrm{~Hz}, \mathrm{CH}_{3} \mathrm{CH}-\right), 2.0(1 \mathrm{H}$, br s, $\mathrm{OH}), 3.89(1 \mathrm{H}, \mathrm{dd}, J=10.2$ and $3.7 \mathrm{~Hz}, 6-\mathrm{H}), 4.34(1 \mathrm{H}$, $\mathrm{dq}, J=10.2$ and $\left.6.1 \mathrm{~Hz}, \mathrm{CH}_{3} \mathrm{CH}-\right), 4.6 \sim 4.8(2 \mathrm{H}, \mathrm{m}$, $\left.-\mathrm{C} H_{2} \mathrm{CH}=\right), 5.2 \sim 5.5\left(2 \mathrm{H}, \mathrm{m}, \mathrm{CH}_{2}=\mathrm{CH}-\right), 5.84(1 \mathrm{H}, \mathrm{d}$, $J=3.0 \mathrm{~Hz}, 5-\mathrm{H}), 5.8 \sim 6.0\left(1 \mathrm{H}, \mathrm{m}, \mathrm{CH}_{2}=\mathrm{CH}-\right), 7.31(1 \mathrm{H}$, $\mathrm{s}, 2-\mathrm{H})$; UV $\lambda_{\max }^{\mathrm{EtoH}} \mathrm{nm}(\varepsilon) 253$ (2650), 313 (6780); MS $\mathrm{m} / \mathrm{z}$ $255.0567\left(\mathrm{M}^{+}\right.$, calcd for $\left.\mathrm{C}_{11} \mathrm{H}_{13} \mathrm{NO}_{4} \mathrm{~S} 255.0565\right)$.

Allyl $\left(5 S, 6 S, 1^{\prime} R\right)-6-\left(1^{\prime}\right.$-Acetoxyethyl)penem-3-carboxylate (1b)

A solution of penem (1a) $(480 \mathrm{mg}, 1.88 \mathrm{mmol})$ in $\mathrm{CH}_{2} \mathrm{Cl}_{2}(10 \mathrm{ml})$ was ice-cooled and treated with $\mathrm{Et}_{3} \mathrm{~N}$ $(0.52 \mathrm{ml}), \mathrm{Ac}_{2} \mathrm{O}(0.44 \mathrm{ml})$ and a catalytic quantity of DMAP. After 30 minutes, the solution was diluted with EtOAc, washed with $0.5 \mathrm{~N} \mathrm{H}_{2} \mathrm{SO}_{4}$, water and $\mathrm{NaHCO}_{3}$ solution, dried and evaporated. Chromatography gave 1b (543 mg, 97\%). Crystallisation from EtOAc-hexane gave colourless needles: MP $45 \sim 46^{\circ} \mathrm{C} ;[\alpha]_{\mathrm{D}}^{20}-264^{\circ}(c$ $\left.0.6, \mathrm{CHCl}_{3}\right)$; IR $v_{\max }\left(\mathrm{CHCl}_{3}\right) \mathrm{cm}^{-1} 1795,1730,1715$, 1655,$1560 ;{ }^{1} \mathrm{H} \mathrm{NMR}\left(\mathrm{CDCl}_{3}\right) \delta 1.52(3 \mathrm{H}, \mathrm{d}, J=6.3 \mathrm{~Hz}$, $\left.\mathrm{CH}_{3} \mathrm{CH}-\right), 2.05(3 \mathrm{H}, \mathrm{s}, \mathrm{OAc}), 4.06(1 \mathrm{H}, \mathrm{ddd}, J=10.2,4$ and $0.8 \mathrm{~Hz}, 6-\mathrm{H}), 4.6 \sim 4.8\left(2 \mathrm{H}, \mathrm{m},-\mathrm{CH}_{2} \mathrm{CH}_{=}\right), 5.2 \sim 5.5$ $\left(3 \mathrm{H}, \mathrm{m}, \mathrm{CH}_{2}=\mathrm{CH}-\right.$ and $\left.\mathrm{CH}_{3} \mathrm{CH}-\right), 5.83(1 \mathrm{H}, \mathrm{d}$, $J=4.2 \mathrm{~Hz}, 5-\mathrm{H}), 5.8 \sim 6.1\left(1 \mathrm{H}, \mathrm{m}, \mathrm{CH}_{2}=\mathrm{CH}-\right), 7.31(1 \mathrm{H}$, $\mathrm{d}, J=0.8 \mathrm{~Hz}, 2-\mathrm{H})$; UV $\lambda_{\max }^{\mathrm{EtOH}} \mathrm{nm}(\varepsilon) 255(1830), 313$ (5870).

$$
\begin{array}{ll}
\text { Anal Calcd for } \mathrm{C}_{13} \mathrm{H}_{15} \mathrm{NO}_{5} \mathrm{~S}: & \mathrm{C} 52.5, \mathrm{H} 5.1, \mathrm{~N} 4.7 . \\
\begin{array}{ll}
\text { Found: } & \text { C } 52.7, \mathrm{H} 5.1, \mathrm{~N} 4.8 .
\end{array}
\end{array}
$$

Allyl $\left(5 S, 6 S, 1^{\prime} R\right)-6-\left(1^{\prime}-\right.$ Palmitoyloxyethyl)penem-3carboxylate (1c)

A solution of penem (1a) $(51 \mathrm{mg}, 0.2 \mathrm{mmol})$ in $\mathrm{CH}_{2} \mathrm{Cl}_{2}$ $(2 \mathrm{ml})$ was treated with $\mathrm{Et}_{3} \mathrm{~N}(0.14 \mathrm{ml})$, palmitoyl chloride $(275 \mathrm{mg})$ and a catalytic quantity of DMAP. After 1 hour, the solution was diluted with EtOAc, washed with $0.5 \mathrm{~N} \mathrm{H}_{2} \mathrm{SO}_{4}$, water and $\mathrm{NaHCO}_{3}$ solution, dried and evaporated. Chromatography gave (1c) as a gum $(70 \mathrm{mg}$, $72 \%) ;[\alpha]_{\mathrm{D}}^{21}-172^{\circ}\left(c 0.7, \mathrm{CHCl}_{3}\right) ; \mathrm{IR} v_{\max }\left(\mathrm{CHCl}_{3}\right)$ $\mathrm{cm}^{-1} 1795,1720,1650,1565 ;{ }^{1} \mathrm{H}$ NMR $\left(\mathrm{CDCl}_{3}\right) \delta 0.88$ $\left(3 \mathrm{H}, \mathrm{t},-\mathrm{CH}_{2} \mathrm{CH}_{3}\right), 1.28(24 \mathrm{H}, \mathrm{s}$, palmitoyl), $1.51(3 \mathrm{H}$, $\left.\mathrm{d}, J=6.3 \mathrm{~Hz}, \mathrm{CH}_{3} \mathrm{CH}-\right), 1.60\left(2 \mathrm{H}, \mathrm{m},-\mathrm{CH}_{2} \mathrm{CH}_{2} \mathrm{CO}-\right)$, $2.27\left(2 \mathrm{H}, \mathrm{t},-\mathrm{CH}_{2} \mathrm{CO}\right), 4.06(1 \mathrm{H}, \mathrm{ddd}, J=10.2,3.9$ and $0.7 \mathrm{~Hz}, 6-\mathrm{H}), 4.6 \sim 4.8\left(2 \mathrm{H}, \mathrm{m},-\mathrm{CH}_{2} \mathrm{CH}=\right), 5.2 \sim 5.4(3 \mathrm{H}$, $\mathrm{m}, \mathrm{CH}_{2}=\mathrm{CH}-$ and $\left.\mathrm{CH}_{3} \mathrm{CH}-\right), 5.82(1 \mathrm{H}, \mathrm{d}, J=4.0 \mathrm{~Hz}$, $5-\mathrm{H}), \quad 5.8 \sim 6.1\left(1 \mathrm{H}, \mathrm{m}, \mathrm{CH}_{2}=\mathrm{CH}-\right), 7.31(1 \mathrm{H}, \mathrm{d}$, $J=0.7 \mathrm{~Hz}, 2-\mathrm{H})$; UV $\lambda_{\max }^{\mathrm{EtOH}} \mathrm{nm}(\varepsilon) 256(2930), 311(7500)$; FAB-MS (matrix 3-NOBA-Na) $m / z 516(70 \%, \mathrm{M}+\mathrm{Na})$, $170(100 \%)$. 
Allyl $\left(5 S, 6 S, 1^{\prime} R\right)-6-\left(1^{\prime}\right.$-Benzoyloxyethyl)penem-3carboxylate (1j)

Analogous preparation to that for $\mathbf{1 c}$ gave $\mathbf{1 j}$ as colourless needles $(59 \%)$; MP $146 \sim 148^{\circ} \mathrm{C} ;[\alpha]_{\mathrm{D}}^{22}-283^{\circ}$ (c $0.5, \mathrm{CHCl}_{3}$ ); IR $v_{\max }(\mathrm{KBr}) \mathrm{cm}^{-1} 1791,1702,1648$, $1555 ;{ }^{1} \mathrm{H}$ NMR $\left(\mathrm{CDCl}_{3}\right) \delta 1.68(3 \mathrm{H}, \mathrm{d}, J=6.3 \mathrm{~Hz}$, $\left.\mathrm{CH}_{3} \mathrm{CH}-\right), 4.22(1 \mathrm{H}, \mathrm{dd}, J=9.8$ and $4.3 \mathrm{~Hz}, 6-\mathrm{H})$, $4.6 \sim 4.8 \quad\left(2 \mathrm{H}, \quad \mathrm{m},-\mathrm{CH}_{2} \mathrm{CH}=\right), \quad 5.2 \sim 5.5 \quad(2 \mathrm{H}, \mathrm{m}$, $\left.\mathrm{CH}_{2}=\mathrm{CH}-\right), 5.5 \sim 5.7\left(1 \mathrm{H}, \mathrm{m}, \mathrm{CH}_{3} \mathrm{CH}-\right), 5.91(1 \mathrm{H}, \mathrm{d}$, $J=4.0 \mathrm{~Hz}, 5-\mathrm{H}), 5.9 \sim 6.1\left(1 \mathrm{H}, \mathrm{m}, \mathrm{CH}_{2}=\mathrm{CH}-\right), 7.33(1 \mathrm{H}$, s, $2-\mathrm{H}), 7.4 \sim 7.5(2 \mathrm{H}, \mathrm{m}, \mathrm{Ar}-\mathrm{H}), 7.55 \sim 7.7(1 \mathrm{H}, \mathrm{m}, \mathrm{Ar}-\mathrm{H})$, $7.9 \sim 8.1(2 \mathrm{H}, \mathrm{m}, \mathrm{Ar}-\mathrm{H}) ; \mathrm{UV} \lambda_{\max }^{\mathrm{EtOH}} \mathrm{nm}(c) 229$ (14975), $313(7150)$.

Anal Calcd for $\mathrm{C}_{18} \mathrm{H}_{17} \mathrm{NO}_{5} \mathrm{~S}: \quad \mathrm{C} 60.2, \mathrm{H} 4.8, \mathrm{~N} 3.9, \mathrm{~S} 8.9$. Found:

C 60.2, H 4.7, N 4.0, S 8.7.

3,4-(Bis- $t$-butyldiphenylsilyloxy)benzoic Acid (9)

A solution of 3,4-dihydroxybenzoic acid $(308 \mathrm{mg}$, $2 \mathrm{mmol})$ in DMF $(4 \mathrm{ml})$ was treated with imidazole $(560 \mathrm{mg})$ and $t$-butyldiphenylsilyl chloride $(2.08 \mathrm{ml})$. After stirring for 3 days, the mixture was diluted with EtOAc, washed with $0.5 \mathrm{~N} \mathrm{H}_{2} \mathrm{SO}_{4}$ and water, dried and evaporated. Chromatography gave $t$-butyldiphenylsilyl 3,4-(bis- $t$-butyldiphenylsilyloxy)benzoate as a white foam $(1.5 \mathrm{~g}, 86 \%)$ : IR $v_{\max }\left(\mathrm{CHCl}_{3}\right) \mathrm{cm}^{-1} 1696 ;{ }^{1} \mathrm{H} \mathrm{NMR}$ $\left(\mathrm{CDCl}_{3}\right) \delta 0.79(9 \mathrm{H}, \mathrm{s}, t \mathrm{Bu}), 1.16(18 \mathrm{H}, \mathrm{s}, t \mathrm{Bu}), 6.46(1 \mathrm{H}$, $\mathrm{d}, J=8.5 \mathrm{~Hz}, \mathrm{Ar}-\mathrm{H}), 7.1 \sim 7.9(32 \mathrm{H}, \mathrm{m}, \mathrm{Ar}-\mathrm{H})$. A solution of this ester in $\mathrm{MeOH}(12 \mathrm{ml})+\mathrm{CH}_{2} \mathrm{Cl}_{2}(8 \mathrm{ml})$ was treated with a solution of $\mathrm{KF}(110 \mathrm{mg})$ in $\mathrm{MeOH}(3 \mathrm{ml})$. After 1 hour the solution was diluted with EtOAc, washed with $0.5 \mathrm{~N} \mathrm{H}_{2} \mathrm{SO}_{4}$ and water, dried and evaporated. Crystallisation from EtOAc-hexane gave the acid (9) as white microcrystals $(823 \mathrm{mg}, 75 \%)$ : MP $237 \sim 239^{\circ} \mathrm{C}$; IR $v_{\max }(\mathrm{KBr}) \mathrm{cm}^{-1} 1682,1596,1577,1515 ;{ }^{1} \mathrm{H}$ NMR $\left(\mathrm{CDCl}_{3}\right) \delta 1.12(9 \mathrm{H}, \mathrm{s}, t \mathrm{Bu}), 1.19(9 \mathrm{H}, \mathrm{s}, t \mathrm{Bu}), 6.40(1 \mathrm{H}$, $\mathrm{d}, J=8.4 \mathrm{~Hz}, \mathrm{Ar}-\mathrm{H}), 7.09(1 \mathrm{H}, \mathrm{dd}, J=6.4$ and $2.0 \mathrm{~Hz}$, Ar-H), $7.19(1 \mathrm{H}, \mathrm{d}, J=2.0 \mathrm{~Hz}, \mathrm{Ar}-\mathrm{H}), 7.3 \sim 7.9(20 \mathrm{H}, \mathrm{m}$, $\mathrm{Ph})$; UV $\lambda_{\max }^{\mathrm{EtOH}} \mathrm{nm}(\varepsilon) 252$ (12170), 291 (3580).

Anal Calcd for $\mathrm{C}_{39} \mathrm{H}_{42} \mathrm{NO}_{4} \mathrm{Si}_{2}$ : C 74.2, $\mathrm{H} 6.7$. Found:

C 74.2, H 6.9 .

3,4-(Bis- $t$-butyldiphenylsilyloxy)phenylacetic Acid (11)

Analogous preparation to that for 9 and isolation by chromatography gave $\mathbf{1 1}$ as a white foam (89\%): IR $v_{\text {max }}\left(\mathrm{CHCl}_{3}\right) \mathrm{cm}^{-1} 1711,1605,1580,1510 ;{ }^{1} \mathrm{H}$ NMR $\left(\mathrm{CDCl}_{3}\right) \delta 1.14(9 \mathrm{H}, \mathrm{s}, t \mathrm{Bu}), 1.17(9 \mathrm{H}, \mathrm{s}, t \mathrm{Bu}), 3.06(2 \mathrm{H}$, $\left.\mathrm{s},-\mathrm{CH}_{2} \mathrm{COOH}\right), 6.2 \sim 6.4(3 \mathrm{H}, \mathrm{m}, \mathrm{Ar}-\mathrm{H}), 7.2 \sim 7.5(12 \mathrm{H}$, $\mathrm{m}, \mathrm{Ar}-\mathrm{H}), 7.7 \sim 7.9(8 \mathrm{H}, \mathrm{m}, \mathrm{Ar}-\mathrm{H}) ;$ Electrospray-MS $m / z$ $662\left(100 \%, \mathrm{M}+\mathrm{NH}_{4}\right)$.

Allyl $\left(5 S, 6 S, 1^{\prime} R\right)-6$-[1'-( $t$-Butyldiphenylsilyloxy)acetoxyethyl]penem-3-carboxylate (6): General Method for Carbodiimide/DMAP-mediated Coupling

A solution of penem (1a) $(51 \mathrm{mg}, 0.2 \mathrm{mmol})$ and 5 (250 mg, $0.8 \mathrm{mmol})$ in $\mathrm{CH}_{2} \mathrm{Cl}_{2}(1 \mathrm{ml})$ was cooled to $-15^{\circ} \mathrm{C}$ and treated with DMAP $(25 \mathrm{mg}, 0.2 \mathrm{mmol})$ and 1-dimethylaminopropyl-3-ethylcarbodiimide hydro- chloride $(300 \mathrm{mg})$. The reaction was stirred for 20 minutes at $-15^{\circ} \mathrm{C}$ and 30 minutes at $0^{\circ} \mathrm{C}$, diluted with EtOAc, washed with $0.5 \mathrm{~N} \mathrm{H}_{2} \mathrm{SO}_{4}$, water and $\mathrm{NaHCO}_{3}$ solution, dried and evaporated. Chromatography gave 6 as a gum (98 mg, 89\%): $\left.[\alpha]_{\mathrm{D}}^{19}-138^{\circ}(c) 1.5, \mathrm{CHCl}_{3}\right)$; IR $v_{\max }$ $\left(\mathrm{CHCl}_{3}\right) \mathrm{cm}^{-1} 1795,1765,1715,1650,1560 ;{ }^{1} \mathrm{H}$ NMR $\left(\mathrm{CDCl}_{3}\right) \delta 1.10(9 \mathrm{H}, \mathrm{s}, t \mathrm{Bu}), 1.46(3 \mathrm{H}, \mathrm{d}, J=6.3 \mathrm{~Hz}$, $\left.\mathrm{CH}_{3} \mathrm{CH}-\right), 3.92(1 \mathrm{H}$, ddd, $J=10.5,4.0$ and $0.7 \mathrm{~Hz}, 6-\mathrm{H})$, $4.23\left(2 \mathrm{H}, \mathrm{s},-\mathrm{COCH}_{2} \mathrm{O}-\right), 4.6 \sim 4.8\left(2 \mathrm{H}, \mathrm{m},-\mathrm{CH}_{2} \mathrm{CH}=\right)$, $5.2 \sim 5.5\left(3 \mathrm{H}, \mathrm{m}, \mathrm{CH}{ }_{2}=\mathrm{CH}-\right.$ and $\left.\mathrm{CH}_{3} \mathrm{CH}-\right), 5.68(1 \mathrm{H}$, $\mathrm{d}, J=4.0 \mathrm{~Hz}, 5-\mathrm{H}), 5.8 \sim 6.0\left(1 \mathrm{H}, \mathrm{m}, \mathrm{CH}_{2}=\mathrm{CH}-\right), 7.29$ $(1 \mathrm{H}, \mathrm{d}, J=0.7 \mathrm{~Hz}, 2-\mathrm{H}), 7.3 \sim 7.5(6 \mathrm{H}, \mathrm{m}, \mathrm{Ph}-\mathrm{H}), 7.6 \sim 7.7$ (4H, m, Ph-H); UV $\lambda_{\max }^{\mathrm{EtOH}} \mathrm{nm}(\varepsilon) 258$ (3930), 312 (8310); FAB-MS (matrix 3-NOBA-Na) $m / z 574(30 \%, \mathrm{M}+\mathrm{Na})$, $359(80 \%), 170(100 \%)$.

In a similar way were made the following:

Allyl $\left(5 S, 6 S, 1^{\prime} R\right)-6-\left(1^{\prime}-p\right.$-Nitrobenzylsuccinyloxyethyl]penem-3-carboxylate (8)

Gum $(90 \%)$ : IR $v_{\max }\left(\mathrm{CHCl}_{3}\right) \mathrm{cm}^{-1} 1795,1735,1670$, $1615,1560,1520 ;{ }^{1} \mathrm{H} \mathrm{NMR}\left(\mathrm{CDCl}_{3}\right) \delta 1.51(3 \mathrm{H}, \mathrm{d}$, $\left.J=6.3 \mathrm{~Hz}, \mathrm{CH}_{3} \mathrm{CH}-\right), 2.5 \sim 2.9\left(4 \mathrm{H}, \mathrm{m},-\mathrm{CH}_{2} \mathrm{CH}_{2}-\right), 4.08$ $(1 \mathrm{H}, \mathrm{ddd}, J=10.0,4.0$ and $0.7 \mathrm{~Hz}, 6-\mathrm{H}), 4.6 \sim 4.8(2 \mathrm{H}$, $\left.\mathrm{m},-\mathrm{CH}_{2} \mathrm{CH}=\right), 5.2 \sim 5.5\left(5 \mathrm{H}, \mathrm{m},-\mathrm{CH}_{2} \mathrm{Ar}, \mathrm{CH}_{2}=\mathrm{CH}-\right.$ and $\left.\mathrm{CH}_{3} \mathrm{CH}-\right), 5.79(1 \mathrm{H}, \mathrm{d}, J=4.0 \mathrm{~Hz}, 5-\mathrm{H}), 5.8 \sim 6.0$ $\left(1 \mathrm{H}, \mathrm{m}, \mathrm{CH}_{2}=\mathrm{CH}-\right), 7.32(1 \mathrm{H}, \mathrm{d}, J=0.8 \mathrm{~Hz}, 2-\mathrm{H}), 7.52$ ( $2 \mathrm{H}, \mathrm{d}, \mathrm{Ar}-\mathrm{H}), 8.22$ (2H, d, Ar-H); Thermospray-MS $m / z$ $508\left(100 \%, \mathrm{M}+\mathrm{NH}_{4}\right)$.

Allyl $\left(5 S, 6 S, 1^{\prime} R\right)-6-\left[1^{\prime}-(3,4-B i s-t\right.$-butyldiphenylsilyloxybenzoyloxy)ethyl]penem-3-carboxylate (10)

$\operatorname{Gum}(20 \%):[\alpha]_{\mathrm{D}}^{20}-98^{\circ}\left(c \quad 0.8, \mathrm{CHCl}_{3}\right)$; IR $v_{\max }$ $\left(\mathrm{CHCl}_{3}\right) \mathrm{cm}^{-1} 1794,1715,1660,1600,1585,1570,1515$; ${ }^{1} \mathrm{H}$ NMR $\left(\mathrm{CDCl}_{3}\right) \delta 1.14(9 \mathrm{H}, \mathrm{s}, t \mathrm{Bu}), 1.18(9 \mathrm{H}, \mathrm{s}, t \mathrm{Bu})$, $1.33\left(3 \mathrm{H}, \mathrm{d}, J=6.2 \mathrm{~Hz}, \mathrm{CH}_{3} \mathrm{CH}-\right), 3.73(1 \mathrm{H}, \mathrm{dd}, J=10.2$ and $4.1 \mathrm{~Hz}, 6-\mathrm{H}), 4.6 \sim 4.8\left(2 \mathrm{H}, \mathrm{m},-\mathrm{CH}_{2} \mathrm{CH}=\right), 5.16(1 \mathrm{H}$, $\mathrm{dq}, J=10.3$ and $\left.6.2 \mathrm{~Hz}, \mathrm{CH}_{3} \mathrm{CH}-\right), 5.2 \sim 5.4(3 \mathrm{H}, \mathrm{m}, 5-\mathrm{H}$ and $\left.\mathrm{CH}_{2}=\mathrm{CH}-\right), 5.8 \sim 6.0\left(1 \mathrm{H}, \mathrm{m}, \mathrm{CH}_{2}=\mathrm{CH}-\right), 6.44(1 \mathrm{H}$, $\mathrm{d}, J=9.0 \mathrm{~Hz}, \mathrm{Ar}-\mathrm{H}), 7.0 \sim 7.1(2 \mathrm{H}, \mathrm{m}, \mathrm{Ar}-\mathrm{H}), 7.21(1 \mathrm{H}$, d, $J=0.6 \mathrm{~Hz}, 2-\mathrm{H}), 7.3 \sim 7.5(12 \mathrm{H}, \mathrm{m}, \mathrm{Ph}-\mathrm{H}), 7.7 \sim 7.8$ (8H, m, Ph-H); UV $\lambda_{\text {max }}^{\mathrm{EtOH}} \mathrm{nm}(\varepsilon) 261$ (18140), 302 (13100); FAB-MS (matrix 3-NOBA-Na) $m / z 890(35 \%, \mathrm{M}+\mathrm{Na})$, $613(100 \%)$.

Allyl $\left(5 S, 6 S, 1^{\prime} R\right)-6-\left[1^{\prime}-(3,4-B i s-t\right.$-butyldiphenylsilyloxyphenylacetyloxy)ethyl]penem-3-carboxylate (12)

White foam $(100 \%)$ : IR $v_{\max }\left(\mathrm{CHCl}_{3}\right) \mathrm{cm}^{-1} 1792,1718$, $1650,1604,1575,1561,1514 ;{ }^{1} \mathrm{H}$ NMR $\left(\mathrm{CDCl}_{3}\right) \delta 1.14$ $(9 \mathrm{H}, \mathrm{s}, t \mathrm{Bu}), 1.17(9 \mathrm{H}, \mathrm{s}, t \mathrm{Bu}), 1.27(3 \mathrm{H}, \mathrm{d}, J=6.3 \mathrm{~Hz}$, $\left.\mathrm{CH}_{3} \mathrm{CH}-\right), 2.99\left(2 \mathrm{H}, \mathrm{s},-\mathrm{CH}_{2} \mathrm{Ar}\right), 3.59(1 \mathrm{H}, \mathrm{dd}, J=10.0$ and $3.9 \mathrm{~Hz}, 6-\mathrm{H}), 4.6 \sim 4.8\left(2 \mathrm{H}, \mathrm{m},-\mathrm{CH}_{2} \mathrm{CH}=\right), 4.98(1 \mathrm{H}$, $\mathrm{dq}, J=10.4$ and $\left.6.2 \mathrm{~Hz}, \mathrm{CH}_{3} \mathrm{CH}-\right), 5.19(1 \mathrm{H}, \mathrm{d}$, $J=4.2 \mathrm{~Hz}, 5-\mathrm{H}), 5.2 \sim 5.5\left(2 \mathrm{H}, \mathrm{m}, \mathrm{CH}_{2}=\mathrm{CH}-\right), 5.9 \sim 6.1$ $\left(1 \mathrm{H}, \mathrm{m}, \mathrm{CH}_{2}=\mathrm{CH}-\right), 6.24(1 \mathrm{H}, \mathrm{dd}, J=8.2$ and $2.1 \mathrm{~Hz}$, Ar-H), 6.3-6.4 (2H, m, Ar-H), $7.11(1 \mathrm{H}, \mathrm{d}, J=0.8 \mathrm{~Hz}$, $2-\mathrm{H}), 7.3 \sim 7.5(12 \mathrm{H}, \mathrm{m}, \mathrm{Ph}-\mathrm{H}), 7.7 \sim 7.9(8 \mathrm{H}, \mathrm{m}, \mathrm{Ph}-\mathrm{H})$; UV $\lambda{ }_{\max }^{\text {EtOH }} \mathrm{nm}(\varepsilon) 290(5310), 313$ (6990); FAB-MS (matrix 3-NOBA-Na) $m / z 904$ (25\%, M +Na), $197(100 \%)$. 
Allyl $\left(5 S, 6 S, 1^{\prime} R\right)-6-\left[1^{\prime}-(\right.$ Benzyloxycarbonyl-Lalanyloxy)ethyl]penem-3-carboxylate (1f)

Gum $(60 \%):[\alpha]_{\mathrm{D}}^{21}-250^{\circ}\left(c 0.3, \mathrm{CHCl}_{3}\right) ;$ IR $v_{\max }$ $\left(\mathrm{CHCl}_{3}\right) \mathrm{cm}^{-1} 3420,1795,1715,1660,1565,1510 ;{ }^{1} \mathrm{H}$ $\operatorname{NMR}\left(\mathrm{CDCl}_{3}\right) \delta 1.40\left(3 \mathrm{H}, \mathrm{d}, J=7.2 \mathrm{~Hz}, \mathrm{CH}_{3} \mathrm{CH}-\right), 1.51$ $\left(3 \mathrm{H}, \mathrm{d}, J=6.2 \mathrm{~Hz}, \mathrm{CH}_{3} \mathrm{CH}-\right), 4.06(1 \mathrm{H}, \mathrm{dd}, J=10.1$ and $3.8 \mathrm{~Hz}, 6-\mathrm{H}), 4.28(1 \mathrm{H}$, quintet, $J=7.2 \mathrm{~Hz}$, alanyl $\mathrm{CH})$, $4.6 \sim 4.8\left(2 \mathrm{H}, \mathrm{m},-\mathrm{CH} \mathrm{H}_{2} \mathrm{CH}=\right), 5.11\left(2 \mathrm{H}, \mathrm{s},-\mathrm{CH}_{2} \mathrm{Ph}\right)$, $5.1 \sim 5.5\left(4 \mathrm{H}, \mathrm{m}, \mathrm{NH}, \mathrm{CH}_{2}=\mathrm{CH}-\right.$ and $\left.\mathrm{CH}_{3} \mathrm{CH}-\right), 5.78$ $(1 \mathrm{H}, \mathrm{d}, J=3.9 \mathrm{~Hz}, 5-\mathrm{H}), 5.8 \sim 6.0\left(1 \mathrm{H}, \mathrm{m}, \mathrm{CH}_{2}=\mathrm{C} H-\right)$, $7.2 \sim 7.4(6 \mathrm{H}, \mathrm{m}, \mathrm{Ph}-\mathrm{H}$ and $2-\mathrm{H})$; UV $\lambda_{\max }^{\mathrm{EtOH}} \mathrm{nm}(\varepsilon) 252$ (3400), 312 (7890); FAB-MS (matrix 3-NOBA-Na) $\mathrm{m} / \mathrm{z}$ $483(60 \%, M+N a), 176(100 \%)$.

Ally1 $\left(5 S, 6 S, 1^{\prime} R\right)-6-\left[1^{\prime}\right.$-(Methoxycarbonyl-L-phenylalanyloxy)ethyl]penem-3-carboxylate (1g)

Gum $(83 \%):[\alpha]_{\mathrm{D}}^{20}-200^{\circ}\left(c 0.8, \mathrm{CHCl}_{3}\right)$; IR $v_{\max }$ $\left(\mathrm{CHCl}_{3}\right) \mathrm{cm}^{-1} 3440,1795,1715,1660,1565,1510 ;{ }^{1} \mathrm{H}$ $\operatorname{NMR}\left(\mathrm{CDCl}_{3}\right) \delta 1.42\left(3 \mathrm{H}, \mathrm{d}, J=6.3 \mathrm{~Hz}, \mathrm{CH}_{3} \mathrm{CH}-\right), 3.04$ $\left(2 \mathrm{H}, \mathrm{d}, J=6.5 \mathrm{~Hz},-\mathrm{CH}_{2} \mathrm{Ph}\right), 3.68(3 \mathrm{H}, \mathrm{s}, \mathrm{OMe}), 4.01$ $(1 \mathrm{H}, \mathrm{dd}, J=10.1$ and $4.2 \mathrm{~Hz}, 6-\mathrm{H}), 4.51(1 \mathrm{H}, \mathrm{q}, J=7.3 \mathrm{~Hz}$, $-\mathrm{COCHN}-), 4.6 \sim 4.8\left(2 \mathrm{H}, \mathrm{m},-\mathrm{CH}_{2} \mathrm{CH}=\right), 5.13(1 \mathrm{H}, \mathrm{d}$, $J=7.8 \mathrm{~Hz}, \mathrm{NH}), \quad 5.2 \sim 5.5\left(3 \mathrm{H}, \mathrm{m}, \mathrm{CH}_{2}=\mathrm{CH}-\right.$ and $\left.\mathrm{CH}_{3} \mathrm{CH}-\right), 5.77(1 \mathrm{H}, \mathrm{d}, J=4.0 \mathrm{~Hz}, 5-\mathrm{H}), 5.8 \sim 6.0(1 \mathrm{H}$, $\left.\mathrm{m}, \mathrm{CH}_{2}=\mathrm{CH}-\right), 7.1 \sim 7.4(6 \mathrm{H}, \mathrm{m}, \mathrm{Ph}-\mathrm{H}$ and $2-\mathrm{H})$; UV $\lambda_{\text {max }}^{\text {EtOH }} \mathrm{nm}(\varepsilon) 254$ (2750), 314 (6720); FAB-MS (matrix 3-NOBA-Na) $m / z 483(55 \%, \mathrm{M}+\mathrm{Na}), 176(100 \%)$.

Allyl $\left(5 S, 6 S, 1^{\prime} R\right)-6-\left[1^{\prime}\right.$-(Methoxycarbonyl-D-phenylalanyloxy)ethyl]penem-3-carboxylate (1h)

Gum $(82 \%):[\alpha]_{\mathrm{D}}^{21}-201^{\circ}\left(c 0.9, \mathrm{CHCl}_{3}\right)$; IR $v_{\max }$ $\left(\mathrm{CHCl}_{3}\right) \mathrm{cm}^{-1} 3450,1795,1715,1660,1565,1510 ;{ }^{1} \mathrm{H}$ $\operatorname{NMR}\left(\mathrm{CDCl}_{3}\right) \delta 1.50\left(3 \mathrm{H}, \mathrm{d}, J=6.3 \mathrm{~Hz}, \mathrm{CH}_{3} \mathrm{CH}-\right), 3.04$ $\left(2 \mathrm{H}, \mathrm{d}, J=6.5 \mathrm{~Hz},-\mathrm{CH}_{2} \mathrm{Ph}\right), 3.64(3 \mathrm{H}, \mathrm{s}, \mathrm{OMe}), 3.91$ $(1 \mathrm{H}, \mathrm{dd}, J=10.0$ and $4.0 \mathrm{~Hz}, 6-\mathrm{H}), 4.5 \sim 4.8(3 \mathrm{H}, \mathrm{m}$, $\mathrm{COCHN}-$ and $\left.-\mathrm{CH}_{2} \mathrm{CH}=\right), 5.11(1 \mathrm{H}, \mathrm{d}, J=7.8 \mathrm{~Hz}$, $\mathrm{NH}), 5.2 \sim 5.5\left(3 \mathrm{H}, \mathrm{m}, \mathrm{CH}_{2}=\mathrm{CH}-\right.$ and $\left.\mathrm{CH}_{3} \mathrm{CH}-\right), 5.63$ $(1 \mathrm{H}, \mathrm{d}, J=4.0 \mathrm{~Hz}, 5-\mathrm{H}), 5.8 \sim 6.0\left(1 \mathrm{H}, \mathrm{m}, \mathrm{CH}_{2}=\mathrm{CH}-\right)$, $7.1 \sim 7.4(6 \mathrm{H}, \mathrm{m}, \mathrm{Ph}-\mathrm{H}$ and $2-\mathrm{H})$; UV $\lambda_{\max }^{\mathrm{EtOH}} \mathrm{nm}(\varepsilon) 254$ (3780), 312 (8630); FAB-MS (matrix 3-NOBA-Na) $\mathrm{m} / \mathrm{z}$ $483(35 \%, \mathrm{M}+\mathrm{Na}), 176(100 \%)$.

Allyl $\left(5 S, 6 S, 1^{\prime} R\right)-6-\left[1^{\prime}-(3,4-D i a c e t o x y b e n z o y l o x y)-\right.$ ethyl]penem-3-carboxylate (1k)

Gum $(15 \%):[\alpha]_{\mathrm{D}}^{18}-170^{\circ}\left(c 0.5, \mathrm{CHCl}_{3}\right)$; IR $v_{\max }$ $\left(\mathrm{CHCl}_{3}\right) \mathrm{cm}^{-1} 1790,1720,1650,1605,1585,1560 ;{ }^{1} \mathrm{H}$ $\operatorname{NMR}\left(\mathrm{CDCl}_{3}\right) \delta 1.63\left(3 \mathrm{H}, \mathrm{d}, J=6.3 \mathrm{~Hz}, \mathrm{CH}_{3} \mathrm{CH}-\right), 2.33$ $\left(6 \mathrm{H}, \mathrm{s}, \mathrm{COCH}_{3}\right), 4.20(1 \mathrm{H}, \mathrm{dd}, J=10.0$ and $4.0 \mathrm{~Hz}, 6-\mathrm{H})$, $4.6 \sim 4.8\left(2 \mathrm{H}, \quad \mathrm{m}, \quad-\mathrm{CH}_{2} \mathrm{CH}=\right), \quad 5.2 \sim 5.5 \quad(2 \mathrm{H}, \quad \mathrm{m}$, $\left.\mathrm{CH}_{2}=\mathrm{CH}-\right), 5.54\left(1 \mathrm{H}, \mathrm{dq}, \mathrm{J}=10.0\right.$ and $\left.6.3 \mathrm{~Hz}, \mathrm{CH}_{3} \mathrm{CH}-\right)$, $5.88(1 \mathrm{H}, \quad \mathrm{d}, \quad J=4.0 \mathrm{~Hz}, \quad 5-\mathrm{H}), \quad 5.9 \sim 6.1 \quad(1 \mathrm{H}, \quad \mathrm{m}$, $\left.\mathrm{CH}_{2}=\mathrm{CH}-\right), 7.29(1 \mathrm{H}, \mathrm{d}, J=8.5 \mathrm{~Hz}, \mathrm{Ar}-\mathrm{H}), 7.32(1 \mathrm{H}, \mathrm{d}$, $J=0.8 \mathrm{~Hz}, 2-\mathrm{H}), 7.82(1 \mathrm{H}, \mathrm{d}, J=2.0 \mathrm{~Hz}, \mathrm{Ar}-\mathrm{H}), 7.91(1 \mathrm{H}$, $\mathrm{dd}, J=8.5$ and $2.0 \mathrm{~Hz}, \mathrm{Ar}-\mathrm{H}$ ); $\mathrm{UV} \lambda_{\max }^{\mathrm{EtOH}} \mathrm{nm}(\varepsilon) 236(5880)$, 313 (2680); FAB-MS (matrix 3-NOBA-Na) $\mathrm{m} / \mathrm{z} 498$ $(30 \%, \mathrm{M}+\mathrm{Na}), 176(100 \%)$.
Allyl $\left(5 S, 6 S, 1^{\prime} R\right)-6$-[1'-(3-Pyridylacetoxy)ethyl]penem-3-carboxylate (1n)

Gum $(53 \%):[\alpha]_{\mathrm{D}}^{18}-209^{\circ}\left(c \quad 0.5, \mathrm{CHCl}_{3}\right)$; IR $v_{\max }$ $\left(\mathrm{CHCl}_{3}\right) \mathrm{cm}^{-1} 1792,1717,1650,1563 ;{ }^{1} \mathrm{H} \mathrm{NMR}\left(\mathrm{CDCl}_{3}\right)$ $\delta 1.52\left(3 \mathrm{H}, \mathrm{d}, J=6.3 \mathrm{~Hz}, \mathrm{CH}_{3} \mathrm{CH}-\right), 3.62(2 \mathrm{H}, \mathrm{s}$, $\left.-\mathrm{CH}_{2} \mathrm{Ar}\right), 4.06(1 \mathrm{H}, \mathrm{dd}, J=10.3$ and $4.0 \mathrm{~Hz}, 6-\mathrm{H})$, $4.6 \sim 4.8 \quad\left(2 \mathrm{H}, \quad \mathrm{m}, \quad-\mathrm{CH}_{2} \mathrm{CH}=\right), 5.2 \sim 5.4 \quad(3 \mathrm{H}, \mathrm{m}$, $\mathrm{CH}_{2}=\mathrm{CH}-$ and $\left.\mathrm{CH}_{3} \mathrm{CH}-\right), 5.72(1 \mathrm{H}, \mathrm{d}, J=4.0 \mathrm{~Hz}, 5-\mathrm{H})$, $5.8 \sim 6.0\left(1 \mathrm{H}, \mathrm{m}, \mathrm{CH}_{2}=\mathrm{CH}-\right), 7.25(1 \mathrm{H}, \mathrm{d}, J=0.7 \mathrm{~Hz}$, $2-\mathrm{H}), 7.25 \sim 7.35(1 \mathrm{H}, \mathrm{m}, \mathrm{Ar}-\mathrm{H}), 7.66(1 \mathrm{H}, \mathrm{d}, J=7.9 \mathrm{~Hz}$, Ar-H), 8.54 (2H, br s, Ar-H); UV $\lambda_{\max }^{\text {EtoH }} \mathrm{nm}(\varepsilon) 256(5420)$, 260 (5510), 312 (7400); FAB-MS (matrix thioglycerol) $m / z 375(100 \%, \mathrm{M}+\mathrm{H})$.

Allyl $\left(5 S, 6 S, 1^{\prime} R\right)-6-\left(1^{\prime}-\right.$ Hydroxyacetoxyethyl)penem3-carboxylate (1d)

A solution of the silylated penem (6) $(95 \mathrm{mg}$, $0.17 \mathrm{mmol})$ in THF $(1 \mathrm{ml})$ was treated with $\mathrm{AcOH}$ $(0.06 \mathrm{ml})$ and a THF solution of $1 \mathrm{M} \operatorname{TBAF}(0.35 \mathrm{ml})$. After 1 hour the solution was diluted with EtOAc, washed with water, $\mathrm{NaHCO}_{3}$ solution and water, dried and evaporated. Chromatography gave $1 \mathrm{~d}$ as a gum $(40 \mathrm{mg}$, $74 \%):[\alpha]_{\mathrm{D}}^{19}-248^{\circ}\left(c 0.3, \mathrm{CHCl}_{3}\right)$; IR $v_{\max }\left(\mathrm{CHCl}_{3}\right)$ $\mathrm{cm}^{-1} 3580,1794,1745,1717,1650,1560 ;{ }^{1} \mathrm{H}$ NMR $\left(\mathrm{CDCl}_{3}\right) \delta 1.57\left(3 \mathrm{H}, \mathrm{d}, J=6.3 \mathrm{~Hz}, \mathrm{CH}_{3} \mathrm{CH}-\right), 2.49(1 \mathrm{H}$, br s, $\mathrm{OH}), 4.0 \sim 4.2\left(3 \mathrm{H}, \mathrm{m}, 6-\mathrm{H}\right.$ and $\left.-\mathrm{CH}_{2} \mathrm{OH}\right), 4.6 \sim 4.8$ $\left(2 \mathrm{H}, \mathrm{m},-\mathrm{CH}_{2} \mathrm{CH}=\right), 5.2 \sim 5.5\left(3 \mathrm{H}, \mathrm{m}, \mathrm{CH}_{2}=\mathrm{CH}-\right.$ and $\left.\mathrm{CH}_{3} \mathrm{CH}-\right), 5.85(1 \mathrm{H}, \mathrm{d}, J=4.0 \mathrm{~Hz}, 5-\mathrm{H}), 5.85 \sim 6.05(1 \mathrm{H}$, $\left.\mathrm{m}, \mathrm{CH}_{2}=\mathrm{C} H-\right), 7.33(1 \mathrm{H}, \mathrm{d}, J=0.7 \mathrm{~Hz}, 2-\mathrm{H})$; UV $\lambda_{\text {max }}^{\mathrm{EtOH}}$ $\mathrm{nm}$ (8) 256 (3380), 311 (7610); ionspray-MS $m / z 644$ $\left(10 \%, 2 \mathrm{M}+\mathrm{NH}_{4}\right), 331\left(100 \%, \mathrm{M}+\mathrm{NH}_{4}\right)$.

Allyl (5S,6S, $\left.1^{\prime} R\right)-6-\left(1^{\prime}\right.$-Sodiosuccinyloxyethyl)penem3-carboxylate (1e)

A solution of penem $(8)(170 \mathrm{mg}, 0.35 \mathrm{mmol})$ in THF $(15 \mathrm{ml})$ was ice-cooled, stirred vigorously and treated with $1 \mathrm{M} \mathrm{NH}_{4} \mathrm{Cl}$ solution $(12 \mathrm{ml})$ and iron powder $(1.5 \mathrm{~g})$. After 1.25 hours the mixture was diluted with EtOAc and water, acidified with dil. $\mathrm{H}_{2} \mathrm{SO}_{4}$ to $\mathrm{pH} 2$ and filtered. The layers were separated and the organic washed with water and evaporated. The residue was taken up in THF $(5 \mathrm{ml})$, $0.1 \mathrm{~N} \mathrm{NaHCO}_{3}(5 \mathrm{ml})$ added and stirred 3 hours. After washing with ether, remaining organic solvent was evaporated and the aqueous solution applied to a column of HP20SS resin. Elution with water, then $20 \%$ acetone-water, followed by partial evaporation and freeze-drying of the compound-containing eluate gave 1e as a hygroscopic solid $(35 \mathrm{mg}, 27 \%)$ : $[\alpha]_{\mathrm{D}}^{21}-241^{\circ}(c 0.2$, $\left.\mathrm{H}_{2} \mathrm{O}\right)$; IR $v_{\max }(\mathrm{KBr}) \mathrm{cm}^{-1} 1791,1718,1575,1560 ;{ }^{1} \mathrm{H}$ NMR $\left(\mathrm{D}_{2} \mathrm{O}\right) \delta 1.44\left(3 \mathrm{H}, \mathrm{d}, J=6.3 \mathrm{~Hz}, \mathrm{CH}_{3} \mathrm{CH}^{-}\right)$, $2.3 \sim 2.7\left(4 \mathrm{H}, \mathrm{m},-\mathrm{CH}_{2} \mathrm{CH}_{2}-\right), 4.48(1 \mathrm{H}, \mathrm{dd}, J=9.8$ and $3.8 \mathrm{~Hz}, 6-\mathrm{H}), 4.6 \sim 4.8\left(2 \mathrm{H}, \mathrm{m},-\mathrm{CH}_{2} \mathrm{CH}=\right), 5.2 \sim 5.4(3 \mathrm{H}$, $\mathrm{m}, \mathrm{CH}_{2}=\mathrm{CH}-$ and $\mathrm{CH}_{3} \mathrm{CH}-$ ), $5.9 \sim 6.1(2 \mathrm{H}, \mathrm{m}$ including $1 \mathrm{H}, \mathrm{d}, J=4.0 \mathrm{~Hz}$ at $\delta 5.94,5-\mathrm{H}$ and $\left.\mathrm{CH}_{2}=\mathrm{CH}-\right), 7.69$ $(1 \mathrm{H}, \mathrm{s}, 2-\mathrm{H})$; UV $\lambda_{\max }^{\mathrm{H}_{2} \mathrm{O}} \mathrm{nm}(\varepsilon) 252$ (3120), 316 (6380); FAB-MS (matrix thioglycerol) $\mathrm{m} / \mathrm{z} 378(20 \%, \mathrm{M}+\mathrm{H})$. 
Allyl $\left(5 S, 6 S, 1^{\prime} R\right)-6-\left[1^{\prime}\right.$-(3,4-Dihydroxybenzoyloxy)ethyl]penem-3-carboxylate (11)

Desilylation of (10) was carried out analogously to that of (6) to give 11 as a foam $(72 \%)$ : $[\alpha]_{\mathrm{D}}^{20}-208^{\circ}(c$ $\left.1.3, \mathrm{CHCl}_{3}\right)$; IR $v_{\max }\left(\mathrm{CHCl}_{3}\right) \mathrm{cm}^{-1} 3538,3368,1795$, $1714,1649,1608,1562,1524 ;{ }^{1} \mathrm{H}$ NMR $\left(\mathrm{CDCl}_{3}\right) \delta 1.63$ $\left(3 \mathrm{H}, \mathrm{d}, J=6.4 \mathrm{~Hz}, \mathrm{CH}_{3} \mathrm{CH}-\right), 4.19(1 \mathrm{H}$, ddd, $J=9.7,4.0$ and $0.7 \mathrm{~Hz}, 6-\mathrm{H}), 4.6 \sim 4.8\left(2 \mathrm{H}, \mathrm{m},-\mathrm{CH}_{2} \mathrm{CH}=\right), 5.2 \sim 5.6$ $\left(3 \mathrm{H}, \mathrm{m}, \mathrm{CH}_{2}=\mathrm{CH}-\right.$ and $\left.\mathrm{CH}_{3} \mathrm{CH}-\right), 5.85 \sim 6.05(2 \mathrm{H}, \mathrm{m}$ including $1 \mathrm{H}, \mathrm{d}, J=4.0 \mathrm{~Hz}$ at $5.88 \delta, 5-\mathrm{H}$ and $\mathrm{CH}_{2}=\mathrm{CH}-$ ), $6.44(2 \mathrm{H}$, br s, OH $), 6.91(1 \mathrm{H}, \mathrm{d}, J=8.3 \mathrm{~Hz}, \mathrm{Ar}-\mathrm{H}), 7.35$ $(1 \mathrm{H}, \mathrm{d}, J=0.7 \mathrm{~Hz}, 2-\mathrm{H}), 7.4 \sim 7.6(2 \mathrm{H}, \mathrm{m}, \mathrm{Ar}-\mathrm{H}) ; \mathrm{UV}$ $\lambda_{\max }^{\mathrm{EtOH}} \mathrm{nm}(\varepsilon) 221$ (19440), 264 (11970), 305 (12420); FAB-MS (matrix 3-NOBA-Na) $m / z 414(7 \%, \mathrm{M}+\mathrm{Na}$ ), $176(100 \%)$, (matrix thioglycerol) $\mathrm{m} / \mathrm{z} 392(8 \%, \mathrm{M}+\mathrm{H})$, $149(100 \%)$.

Allyl $\left(5 S, 6 S, 1^{\prime} R\right)-6-\left[1^{\prime}-(3,4-D i h y d r o x y p h e n y 1-\right.$ acetoxy)ethyl]penem-3-carboxylate $(\mathbf{1 m})$

Desilylation of (12) was carried out analogously to that of (6) to give $1 \mathrm{~m}$ as a gum $(80 \%)$ : $[\alpha]_{\mathrm{D}}^{20}-185^{\circ}(c$ 0.4, $\left.\mathrm{CHCl}_{3}\right)$; IR $v_{\max }\left(\mathrm{CHCl}_{3}\right) \mathrm{cm}^{-1} 3550,3410,1795$, $1717,1649,1614,1562,1520 ;{ }^{1} \mathrm{H}$ NMR $\left(\mathrm{CDCl}_{3}\right) \delta 1.49$ $\left(3 \mathrm{H}, \mathrm{d}, J=6.3 \mathrm{~Hz}, \mathrm{CH}_{3} \mathrm{CH}-\right), 3.47\left(2 \mathrm{H}, \mathrm{s},-\mathrm{CH}_{2} \mathrm{Ar}\right), 4.04$ $(1 \mathrm{H}, \mathrm{dd}, J=10.2$ and $4.0 \mathrm{~Hz}, 6-\mathrm{H}), 4.6 \sim 4.8(2 \mathrm{H}, \mathrm{m}$, $\left.-\mathrm{CH}_{2} \mathrm{CH}=\right), 5.2 \sim 5.4\left(3 \mathrm{H}, \mathrm{m}, \mathrm{CH}_{2}=\mathrm{CH}-\right.$ and $\left.\mathrm{CH}_{3} \mathrm{CH}-\right)$, $5.69(1 \mathrm{H}, \mathrm{d}, J=4.0 \mathrm{~Hz}, 5-\mathrm{H}), 5.8 \sim 6.1\left(3 \mathrm{H}, \mathrm{m}, \mathrm{CH}_{2}=\mathrm{CH}-\right.$ and $\mathrm{OH}$, reduces to $1 \mathrm{H}, \mathrm{m}$, on $\mathrm{D}_{2} \mathrm{O}$ exchange), $6.63(1 \mathrm{H}$, $\mathrm{dd}, J=8.0$ and $2.0 \mathrm{~Hz}, \mathrm{Ar}-\mathrm{H}), 6.7 \sim 6.8(2 \mathrm{H}, \mathrm{m}, 2 \mathrm{H}$ and $\operatorname{Ar}-\mathrm{H}), 7.25(1 \mathrm{H}, \mathrm{d}, J=3.6 \mathrm{~Hz}, \mathrm{Ar}-\mathrm{H}) ; \mathrm{UV} \lambda_{\max }^{\mathrm{EtOH}} \mathrm{nm}(\varepsilon)$ 291 (6070), 313 (7100); electrospray-MS $m / z 428$ (100\%, $\mathrm{M}+\mathrm{Na})$.

Allyl $\left(5 S, 6 S, 1^{\prime} R\right)-6-\left(1^{\prime}-\right.$ Carbamoyloxyethyl)penem-3carboxylate (1p)

A solution of penem (1a) (100 mg, $0.39 \mathrm{mmol})$ in EtOAc $(0.3 \mathrm{ml})$ was treated with trichloracetyl isocyanate $(0.3 \mathrm{ml})$ and left for 5 hours. The mixture was diluted with EtOAc, washed with $\mathrm{NaHCO}_{3}$ solution, dried and evaporated. Chromatography caused decomposition of the trichloracetyl carbamate and gave $\mathbf{1 p}$ as a solid (95 mg, 81\%). Crystallisation (EtOAc-hexane) provided colourless needles: MP $161 \sim 163^{\circ} \mathrm{C} ;[\alpha]_{\mathrm{D}}^{21}-290^{\circ}(c 0.7$, $\left.\mathrm{CHCl}_{3}\right)$; IR $v_{\max }(\mathrm{KBr}) \mathrm{cm}^{-1} 3439,3357,3291,3211$, $1776,1717,1661,1620,1553 ;{ }^{1} \mathrm{H}$ NMR $\left(\mathrm{CDCl}_{3}\right) \delta 1.53$ $\left(3 \mathrm{H}, \mathrm{d}, J=6.3 \mathrm{~Hz}, \mathrm{CH}_{3} \mathrm{CH}-\right), 4.06(1 \mathrm{H}, \mathrm{dd}, J=9.9$ and $3.6 \mathrm{~Hz}, 6-\mathrm{H}), 4.60\left(2 \mathrm{H}\right.$, br s $\left.\mathrm{NH}_{2}\right), 4.6 \sim 4.8(2 \mathrm{H}, \mathrm{m}$, $\left.-\mathrm{CH}_{2} \mathrm{CH}=\right), 5.1 \sim 5.4\left(3 \mathrm{H}, \mathrm{m}, \mathrm{CH}_{2}=\mathrm{CH}-\right.$ and $\left.\mathrm{CH}_{3} \mathrm{CH}-\right)$, $5.85(1 \mathrm{H}, \mathrm{d}, J=4.0 \mathrm{~Hz}, 5-\mathrm{H}), 5.85 \sim 6.05(1 \mathrm{H}, \mathrm{m}$, $\left.\mathrm{CH}_{2}=\mathrm{C} H-\right), 7.32(1 \mathrm{H}, \mathrm{d}, J=0.8 \mathrm{~Hz}, 2-\mathrm{H}) ; \mathrm{UV} \lambda_{\max }^{\mathrm{EtOH}} \mathrm{nm}$ (e) 254 (2860), 312 (7790); FAB-MS (matrix 3-NOBANa) $m / z 321(70 \%, \mathrm{M}+\mathrm{Na}), 176(100 \%)$.

Anal Calcd for $\mathrm{C}_{12} \mathrm{H}_{14} \mathrm{~N}_{2} \mathrm{O}_{5} \mathrm{~S}$ :

C 48.3, H 4.7, N 9.4, S 10.8 .

Found:

C 48.2, H 4.6, N 9.4, S 10.8 .
Allyl $\left(5 S, 6 S, 1^{\prime} R\right)-6-\left(1^{\prime}-N\right.$-Methylcarbamoyloxyethyl)penem-3-carboxylate (1q)

A solution of penem (1a) ( $300 \mathrm{mg}, 1.18 \mathrm{mmol})$ in methyl isocyanate $(2.5 \mathrm{ml})$ was treated with a catalytic quantity of DMAP and left for 3 days. The solvent was evaporated and the residue dissolved in toluene, washed with $0.5 \mathrm{~N}$ $\mathrm{H}_{2} \mathrm{SO}_{4}$ and water, dried and evaporated. Chromatography and crystallisation (EtOAc-hexane) gave 1q (200 mg, 54\%) as colourless needles: MP $127 \sim 129^{\circ} \mathrm{C}$; $[\alpha]_{\mathrm{D}}^{20}-256^{\circ}\left(c 0.4, \mathrm{CHCl}_{3}\right) ; \mathrm{IR} v_{\max }\left(\mathrm{CHCl}_{3}\right) \mathrm{cm}^{-1} 3466$, $1793,1717,1650,1561,1520 ;{ }^{1} \mathrm{H}$ NMR $\left(\mathrm{CDCl}_{3}\right) \delta 1.52$ $\left(3 \mathrm{H}, \mathrm{d}, J=6.3 \mathrm{~Hz}, \mathrm{CH}{ }_{3} \mathrm{CH}-\right), 2.80(3 \mathrm{H}, \mathrm{d}, J=4.9 \mathrm{~Hz}$, $\left.\mathrm{C}_{3} \mathrm{NH}\right), 4.03(1 \mathrm{H}, \mathrm{dd}, J=9.9$ and $4.0 \mathrm{~Hz}, 6-\mathrm{H}), 4.60$ $(1 \mathrm{H}$, br s NH$), 4.6 \sim 4.8\left(2 \mathrm{H}, \mathrm{m},-\mathrm{CH}_{2} \mathrm{CH}=\right), 5.1 \sim 5.4$ $\left(3 \mathrm{H}, \mathrm{m}, \mathrm{CH}_{2}=\mathrm{CH}-\right.$ and $\left.\mathrm{CH}_{3} \mathrm{CH}-\right), 5.84(1 \mathrm{H}, \mathrm{d}, J=$ $4.0 \mathrm{~Hz}, 5-\mathrm{H}), 5.85 \sim 6.05\left(1 \mathrm{H}, \mathrm{m}, \mathrm{CH}_{2}=\mathrm{CH}-\right), 7.34(1 \mathrm{H}$, d, $J=0.8 \mathrm{~Hz}, 2-\mathrm{H}) ; \mathrm{UV} \lambda_{\text {max }}^{\mathrm{EtOH}} \mathrm{nm}($ () $252(2940), 312$ (8130); MS $m / z 312.0782\left(\mathrm{M}^{+}\right.$, calcd for $\mathrm{C}_{13} \mathrm{H}_{16} \mathrm{~N}_{2} \mathrm{O}_{5} \mathrm{~S}$ 312.0780).

Anal Calcd for $\mathrm{C}_{13} \mathrm{H}_{16} \mathrm{~N}_{2} \mathrm{O}_{5} \mathrm{~S}$ : C $50.0, \mathrm{H} 5.2, \mathrm{~N} 9.0$. Found:

C $50.0, \mathrm{H} 5.0, \mathrm{~N} 8.8$.

Allyl $\left(5 S, 6 S, 1^{\prime} R\right)-6-\left(1^{\prime}-N\right.$-Phenylcarbamoyloxyethyl)penem-3-carboxylate (1r)

A solution of penem (1a) $(24 \mathrm{mg}, 0.094 \mathrm{mmol})$ in phenyl isocyanate $(0.5 \mathrm{ml})$ was treated with a catalytic quantity of DMAP. After 1 hour the mixture was dissolved in dichloromethane, washed with $1 \mathrm{~N} \mathrm{HCl}$ and brine, dried and evaporated. Chromatography followed by preparative HPLC ( $\mathrm{Cl} 8$ column, eluted with $\mathrm{MeCN}-\mathrm{H}_{2} \mathrm{O} 2: 1$ ) gave $1 \mathbf{r}$ as a gum $(5 \mathrm{mg}, 17 \%)$; IR $v_{\max }\left(\mathrm{CHCl}_{3}\right) \mathrm{cm}^{-1}$ 3430, 3300(br), 1795, 1715, 1650, 1560, 1525; ${ }^{1} \mathrm{H}$ NMR $\left(\mathrm{CDCl}_{3}\right) \delta 1.60\left(3 \mathrm{H}, \mathrm{d}, J=6.3 \mathrm{~Hz}, \mathrm{CH}_{3} \mathrm{CH}-\right), 4.10(1 \mathrm{H}$, ddd, $J=10.2,4.0$ and $0.8 \mathrm{~Hz}, 6-\mathrm{H}), 4.6 \sim 4.8(2 \mathrm{H}, \mathrm{m}$, $\left.-\mathrm{CH}_{2} \mathrm{CH}=\right), 5.2 \sim 5.5\left(3 \mathrm{H}, \mathrm{m}, \mathrm{CH}_{2}=\mathrm{CH}-\right.$ and $\left.\mathrm{CH}_{3} \mathrm{CH}-\right)$, $5.88(1 \mathrm{H}, \mathrm{d}, J=4.0 \mathrm{~Hz}, 5-\mathrm{H}), 5.85 \sim 6.05(1 \mathrm{H}, \mathrm{m}$, $\left.\mathrm{CH}_{2}=\mathrm{CH}-\right), 6.58(1 \mathrm{H}$, br s, $\mathrm{NH}), 7.0 \sim 7.1(1 \mathrm{H}, \mathrm{m}, \mathrm{Ph}-\mathrm{H})$, $7.3 \sim 7.5$ (5H, $\mathrm{m}, \mathrm{Ph}-\mathrm{H}$ and $2-\mathrm{H}$ ); MS (ammonia chemical ionisation) $\mathrm{m} / \mathrm{z} 392\left(5 \%, \mathrm{M}+\mathrm{NH}_{4}\right), 94(100 \%)$.

Allyl (5S,6S,1'R)-6-(1'-Methoxyethyl)penem-3carboxylate (1s)

A solution of penem (1a) $(50 \mathrm{mg}, 0.2 \mathrm{mmol})$ in nitromethane $(2 \mathrm{ml})$ was ice-cooled and treated with powdered $\mathrm{Na}_{2} \mathrm{CO}_{3}(400 \mathrm{mg})$ and trimethyloxonium fluoroborate $(250 \mathrm{mg})$. After stirring for 4 hours with ice cooling and a further 3 hours at room temperature, the mixture was filtered through celite, diluted with $\mathrm{CH}_{2} \mathrm{Cl}_{2}$, washed with water, dried and evaporated. Chromatography gave 1s as a gum $(9 \mathrm{mg}, 17 \%):[\alpha]_{\mathrm{D}}^{21}-210^{\circ}$ $\left(c 1, \mathrm{CHCl}_{3}\right) ; \mathrm{IR} v_{\max }\left(\mathrm{CHCl}_{3}\right) \mathrm{cm}^{-1} 1795,1715,1650$, $1560 ;{ }^{1} \mathrm{H}$ NMR $\left(\mathrm{CDCl}_{3}\right) \delta 1.40(3 \mathrm{H}, \mathrm{d}, J=5.6 \mathrm{~Hz}$, $\left.\mathrm{CH}_{3} \mathrm{CH}-\right), 3.33(3 \mathrm{H}, \mathrm{s}, \mathrm{OMe}), 3.8 \sim 4.0(2 \mathrm{H}, \mathrm{m}, 6-\mathrm{H}$ and $\left.\mathrm{CH}_{3} \mathrm{CH}-\right), 4.6 \sim 4.8\left(2 \mathrm{H}, \mathrm{m},-\mathrm{CH}_{2} \mathrm{CH}=\right), 5.2 \sim 5.5(2 \mathrm{H}$, $\left.\mathrm{m}, \mathrm{CH}_{2}=\mathrm{CH}-\right), 5.81(1 \mathrm{H}, \mathrm{d}, J=3.8 \mathrm{~Hz}, 5-\mathrm{H}), 5.85 \sim 6.05$ $\left(1 \mathrm{H}, \mathrm{m}, \mathrm{CH}_{2}=\mathrm{CH}-\right), 7.31(1 \mathrm{H}, \mathrm{s}, 2-\mathrm{H}) ; \mathrm{UV} \lambda_{\max }^{\mathrm{EiOH}} \mathrm{nm}(\varepsilon)$ 253 (2690), 314 (6520); MS $m / z 269.0726\left(\mathrm{M}^{+}\right.$, calcd for $\left.\mathrm{C}_{12} \mathrm{H}_{15} \mathrm{NO}_{4} \mathrm{~S} 269.0722\right)$. 
Allyl $\left(5 S, 6 S, 1^{\prime} R\right)-6-\left(1^{\prime}-\right.$ Ethoxyethyl)penem-3carboxylate (1t)

Penem (1t) was prepared analogously to (1s), apart from the use of $\mathrm{CH}_{2} \mathrm{Cl}_{2}$ as solvent, to give a gum $(12 \%)$ : $[\alpha]_{\mathrm{D}}^{19}-214^{\circ}\left(c 0.6, \mathrm{CHCl}_{3}\right) ; \mathrm{IR} v_{\max }\left(\mathrm{CHCl}_{3}\right) \mathrm{cm}^{-1} 1795$, $1715,1650,1560 ;{ }^{1} \mathrm{H}$ NMR $\left(\mathrm{CDCl}_{3}\right) \delta 1.18(3 \mathrm{H}, \mathrm{t}, J=$ $\left.7.0 \mathrm{~Hz}, \mathrm{CH}_{3} \mathrm{CH}_{2}-\right), 1.40\left(3 \mathrm{H}, \mathrm{d}, J=5.5 \mathrm{~Hz}, \mathrm{CH}_{3} \mathrm{CH}-\right)$, 3.35 and $3.68\left(2 \mathrm{H}, 2 \mathrm{dq}, J=8.8\right.$ and $\left.7.0 \mathrm{~Hz}, \mathrm{CH}_{3} \mathrm{CH}_{2}-\right)$, $3.8 \sim 4.0\left(2 \mathrm{H}, \mathrm{m}, 6-\mathrm{H}\right.$ and $\left.\mathrm{CH}_{3} \mathrm{CH}-\right), 4.6 \sim 4.8(2 \mathrm{H}, \mathrm{m}$, $\left.\mathrm{CH}_{2} \mathrm{CH}=\right), 5.2 \sim 5.5\left(2 \mathrm{H}, \mathrm{m}, \mathrm{CH}_{2}=\mathrm{CH}-\right), 5.82(1 \mathrm{H}, \mathrm{d}$, $J=3.7 \mathrm{~Hz}, 5-\mathrm{H}), 5.85 \sim 6.05\left(1 \mathrm{H}, \mathrm{m}, \mathrm{CH}_{2}=\mathrm{CH}-\right), 7.33$ $(1 \mathrm{H}, \mathrm{s}, 2-\mathrm{H})$; UV $\lambda_{\max }^{\mathrm{EtOH}} \mathrm{nm}(\varepsilon) 253(3230), 313(7370)$; MS $m / z 283.0882\left(\mathrm{M}^{+}\right.$, calcd for $\left.\mathrm{C}_{13} \mathrm{H}_{17} \mathrm{NO}_{4} \mathrm{~S} 283.0878\right)$.

Allyl $\left(5 S, 6 S, 1^{\prime} R\right)-6-\left(1^{\prime}-\right.$ Methoxymethoxyethyl)penem3-carboxylate (1u)

A solution of penem (1a) $(54 \mathrm{mg}, 0.21 \mathrm{mmol})$ in $\mathrm{CH}_{2} \mathrm{Cl}_{2}$ $(0.2 \mathrm{ml})$ was treated with diisopropylethylamine $(0.14 \mathrm{ml})$ and chloromethylmethyl ether $(0.06 \mathrm{ml})$ and stirred for 18 hours. The solution was diluted with EtOAc, washed with $1 \mathrm{~N} \mathrm{HCl}$ and $\mathrm{NaHCO}_{3}$ solution, dried and evaporated. Chromatography gave $1 \mathrm{u}$ as a gum $(54 \mathrm{mg}$, $85 \%):[\alpha]_{\mathrm{D}}^{20}-235^{\circ}\left(c 0.9, \mathrm{CHCl}_{3}\right)$; IR $v_{\max }\left(\mathrm{CHCl}_{3}\right)$ $\mathrm{cm}^{-1} 1791,1715,1650,1563 ;{ }^{1} \mathrm{H}$ NMR $\left(\mathrm{CDCl}_{3}\right) \delta 1.48$ $\left(3 \mathrm{H}, \mathrm{d}, J=6.2 \mathrm{~Hz}, \mathrm{CH}_{3} \mathrm{CH}-\right), 3.38(3 \mathrm{H}, \mathrm{s}, \mathrm{OMe}), 3.98$ $(1 \mathrm{H}, \mathrm{ddd}, J=10.3,4.0$ and $0.8 \mathrm{~Hz}, 6-\mathrm{H}), 4.1 \sim 4.25(1 \mathrm{H}$, $\left.\mathrm{m}, \mathrm{CH}_{3} \mathrm{CH}-\right), 4.6 \sim 4.8\left(4 \mathrm{H}, \quad \mathrm{m},-\mathrm{CH}_{2} \mathrm{CH}=\right.$ and $\left.-\mathrm{OCH}_{2} \mathrm{O}-\right), 5.2 \sim 5.5\left(2 \mathrm{H}, \mathrm{m}, \mathrm{CH}_{2}=\mathrm{CH}-\right), 5.84(1 \mathrm{H}$, $\mathrm{d}, J=4.0 \mathrm{~Hz}, 5-\mathrm{H}), 5.85 \sim 6.05\left(1 \mathrm{H}, \mathrm{m}, \mathrm{CH}_{2}=\mathrm{CH}-\right)$, $7.32(1 \mathrm{H}, \mathrm{d}, J=0.8 \mathrm{~Hz}, 2-\mathrm{H}) ; \mathrm{UV} \lambda_{\max }^{\mathrm{EtOH}} \mathrm{nm}(\varepsilon) 252$ (3130), 314 (7700); MS $m / z 299.0833\left(\mathrm{M}^{+}\right.$, calcd for $\left.\mathrm{C}_{13} \mathrm{H}_{17} \mathrm{NO}_{5} \mathrm{~S} 299.0827\right)$.

Allyl $\left(5 S, 6 S, 1^{\prime} R\right)-6$-(1'-Ethoxycarbonylmethoxyethyl)penem-3-carboxylate (1v)

A solution of penem (1a) $(25 \mathrm{mg}, 0.1 \mathrm{mmol})$ in $\mathrm{CH}_{2} \mathrm{Cl}_{2}$ $(0.5 \mathrm{ml})$ at $0^{\circ} \mathrm{C}$ was treated with boron trifluoride etherate $(3 \mathrm{mg})$ and ethyl diazoacetate $(0.02 \mathrm{ml})$ and stored at $4{ }^{\circ} \mathrm{C}$ for 3 days. Chromatography gave $1 v$ as a gum $(5 \mathrm{mg}$, $15 \%):[\alpha]_{\mathrm{D}}^{20}-228^{\circ}\left(c 0.1, \mathrm{CHCl}_{3}\right)$; IR $v_{\max }\left(\mathrm{CHCl}_{3}\right)$ $\mathrm{cm}^{-1} 1790,1752,1716,1650,1560 ;{ }^{1} \mathrm{H}$ NMR $\left(\mathrm{CDCl}_{3}\right)$ $\delta 1.30\left(3 \mathrm{H}, \mathrm{t}, J=7.2 \mathrm{~Hz}, \mathrm{CH}_{3} \mathrm{CH}_{2}\right), 1.45(3 \mathrm{H}, \mathrm{d}, J=$ $\left.5.4 \mathrm{~Hz}, \quad \mathrm{CH}_{3} \mathrm{CH}-\right), \quad 4.0 \sim 4.1 \quad(3 \mathrm{H}, \mathrm{m},-\mathrm{OCH} \mathrm{HCO}-$, $\mathrm{CH}_{3} \mathrm{CH}-$ and $\left.6-\mathrm{H}\right), 4.13(1 \mathrm{H}, \mathrm{d}, J=15.8 \mathrm{~Hz},-\mathrm{OCHH}-$ $\mathrm{CO}-), 4.23\left(2 \mathrm{H}, \mathrm{q}, J=7.2 \mathrm{~Hz},-\mathrm{OCH}_{2} \mathrm{CH}_{3}\right), 4.6 \sim 4.8$ $\left(2 \mathrm{H}, \mathrm{m},-\mathrm{CH} \mathrm{H}_{2} \mathrm{CH}=\right), 5.2 \sim 5.5\left(2 \mathrm{H}, \mathrm{m}, \mathrm{CH}_{2}=\mathrm{CH}-\right), 5.89$ $(1 \mathrm{H}, \mathrm{d}, J=3.7 \mathrm{~Hz}, 5-\mathrm{H}), 5.9 \sim 6.0\left(1 \mathrm{H}, \mathrm{m}, \mathrm{CH}_{2}=\mathrm{CH}-\right)$, $7.31(1 \mathrm{H}, \mathrm{s}, 2-\mathrm{H})$; UV $\lambda_{\max }^{\mathrm{EIOH}} \mathrm{nm}(\varepsilon) 314(7500) ; \mathrm{MS} m / z$ $341.0937\left(\mathrm{M}^{+}\right.$, calcd for $\left.\mathrm{C}_{15} \mathrm{H}_{19} \mathrm{NO}_{6} \mathrm{~S} 341.0933\right)$.

Allyl $\left(5 S, 6 S, 1^{\prime} R\right)-6$-(1'-Sodiosulfatoethyl)penem3-carboxylate (1x)

A solution of penem (1a) $(51 \mathrm{mg}, 0.2 \mathrm{mmol})$ in pyridine $(1 \mathrm{ml})$ was ice-cooled and treated with trimethylsilyl chlorosulfate $(0.1 \mathrm{ml}, 0.6 \mathrm{mmol})$. After 4 hours, the solvent was evaporated and the residue chromatographed on silica: non-polar material was eluted with EtOAc and the required compound with $n$-butanol - ethanol - water $(4: 1: 1)$. After evaporation of butanol and ethanol, the remaining solution was adjusted to $\mathrm{pH} 7$ with dil. $\mathrm{NaOH}$ and passed through a column of Amberlite IR120(Na). The solution of sodium salt was finally chromatographed on HP20SS resin, eluting with water and then $20 \%$ acetone-water. An aqueous solution was freeze-dried to provide $1 \mathrm{x}$ as a white solid $(12.5 \mathrm{mg}, 17.5 \%)$ : $[\alpha]_{\mathrm{D}}^{20}-268^{\circ}$ $\left(c 0.1 ; \mathrm{H}_{2} \mathrm{O}\right)$; IR $v_{\max }(\mathrm{KBr}) \mathrm{cm}^{-1} 1786,1713,1645,1560$, 1268,$1220 ;{ }^{1} \mathrm{H}$ NMR $\left(\mathrm{D}_{2} \mathrm{O}\right) \delta 1.58(3 \mathrm{H}, \mathrm{d}, J=6.3 \mathrm{~Hz}$, $\left.\mathrm{CH}_{3} \mathrm{CH}-\right), 4.39(1 \mathrm{H}, \mathrm{dd}, J=10.0$ and $3.8 \mathrm{~Hz}, 6-\mathrm{H}), 4.76$ $\left(2 \mathrm{H}, \mathrm{dd}, J=5.4\right.$ and $\left.1.2 \mathrm{~Hz},-\mathrm{CH}_{2} \mathrm{CH}=\right), 4.9 \sim 5.1(1 \mathrm{H}$, $\left.\mathrm{m}, \mathrm{CH}_{3} \mathrm{CH}-\right), 5.3 \sim 5.5\left(2 \mathrm{H}, \mathrm{m}, \mathrm{CH}_{2}=\mathrm{CH}-\right), 5.9 \sim 6.1$ $(2 \mathrm{H}, \mathrm{m}$ including $1 \mathrm{H}, \mathrm{d}, J=4.0 \mathrm{~Hz}$ at $\delta 6.0,5-\mathrm{H}$ and $\left.\mathrm{CH}_{2}=\mathrm{CH}-\right), 7.75(1 \mathrm{H}, \mathrm{d}, J=0.8 \mathrm{~Hz}, 2-\mathrm{H}) ; \mathrm{UV} \lambda_{\max }^{\mathrm{H}_{2} \mathrm{O}} \mathrm{nm}$ (c) 250 (2930), 314 (7560); electrospray-MS $m / z 737$ $(100 \%, 2 \mathrm{M}+\mathrm{Na}), 358(75 \%, \mathrm{M}+\mathrm{H})$.

\section{Acknowledgments}

The authors wish to thank Miss S. Elsmere and Messrs A. E. Cutmore, G. D. Risbridger, G. Powell and R. Dennis for spectroscopic and analytical data.

\section{References}

1) Misra, R. \& T. J. Silhavy: In Emerging Targets in Antibacterial and Antifungal Chemotherapy, Ed., J. SuTCLIFFE \& N. H. GeORGOPAPADAKOU. p. 163, published by Chapman and Hall, 1992

2) Pugsley, A. P.: The complete general secretory pathway in Gram-negative bacteria. Microbiol. Rev. 57: 50 108, 1993

3) DALbey, R. E. \& W. Wickner: Leader peptidase catalyses the release of exported proteins from the outer surface of the E. coli plasma membrane. J. Biol. Chem. 260: $15925 \sim 15931,1985$

4) Moore, K. E. \& S. Miura: A small hydrophobic domain anchors leader peptidase to the cytoplasmic membrane of E. coli. J. Biol. Chem. 262: 8806 8813, 1987

5) Wolfe, P. B.; W. Wickner \& J. GOOdMAN: Sequence of the leader peptidase gene of $E$. coli and the orientation of leader peptidase in the bacterial envelope. J. Biol. Chem. 258: 12073 12080, 1983

6) Allsop, A. E; ; G. Brooks, G. Bruton, S. Coulton, P. D. Edwards, I. K. Hatron, A. C. Kaura, S. D. Maclean, N. D. Pearson, T. C. Smale \& R. Southgate: Penem inhibitors of bacterial signal peptidase. Bioorganic and Med. Chem. Letters 5: 443 448, 1995

7) Inata, H.; R. Tanaka, S. Imajo, Y. Oyama \& M. ISHIGURO: Photoinduced isomerisation of a 5,6-transpenem to a cis-penem. J. Chem. Soc. Chem. Commun.: 285 287, 1991

8) Leanza, W. I.; F. Dininno, D. A. Muthard, R. R. Wilkening, K. J. Wildonger, R. W. RAtClifFe \& G. Christensen: An efficient synthesis of 2-substituted-thio6-hydroxyethyl-penem-3-carboxylic acids via 2-thioxopenams. Tet. 39: 2505 2513, 1983

9) Jones, T. K.; S. G. Mills, R. A. Reamer, D. Askin, R. Desmond, R. P. Volante \& ShinkaI: Total synthesis of the immunosuppressant (-)-FK-506. J. Am. Chem. Soc. 111: $1157 \sim 1159,1989$

10) Broom, N. J. P. (Beecham Group Ltd.): $\beta$-Lactam antibacterial agents and processes for their preparation. GB 2037277B, May 5, 1983 